Beta Vulgaris L تأثير التغذية الورقية بالزنك والبورون في محتوى بعض العناصر الغذائية لنبات البنجر السكري

\author{
وحيدة علي أحمد البدر اني

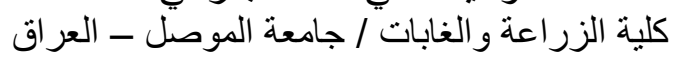 \\ E-mail:wheeda_ali2000@yahoo.com
}

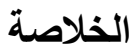

أدت إضافة الزنك و البورون بطريقة الرش على الأوراق بكافة المستويات المضافة سواء منفردين أو متداخلين

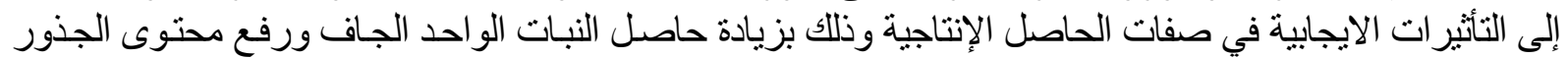

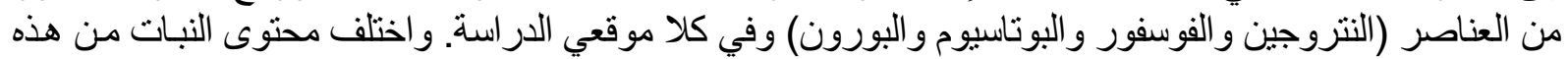

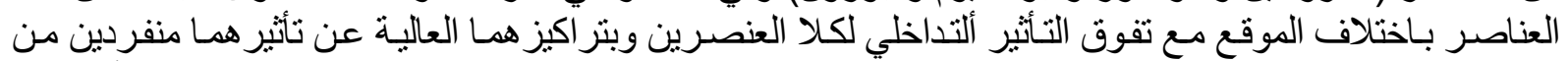

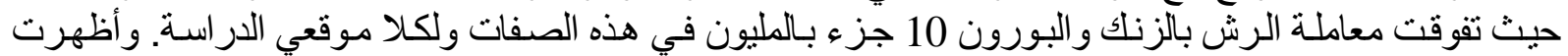

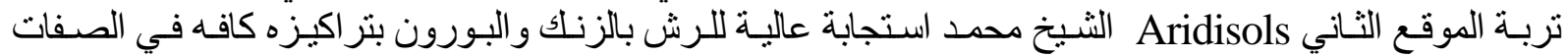

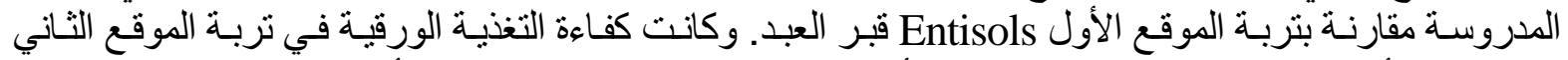

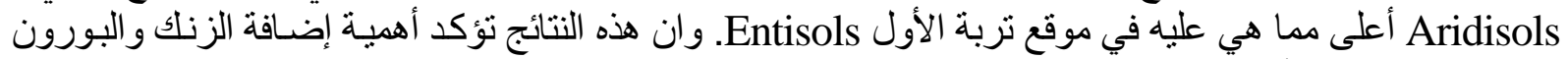

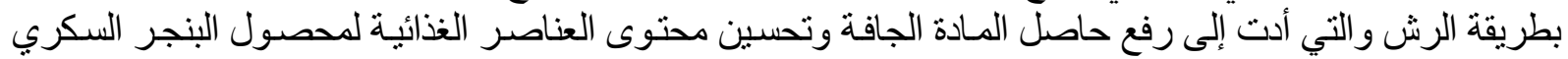
في الترب الكلسية.

الكلمات الدالة: البنجر السكري. الإنتاج، الزنكائه و البورون.

تاريخ تسلم البحث: 2013/2/17 ، وقبوله: 2013/6/24.

\section{المقدمة}

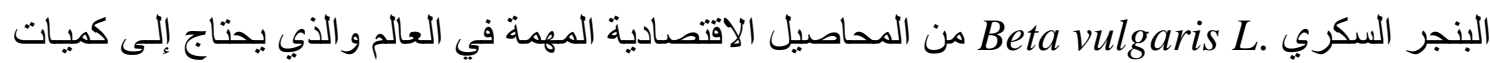

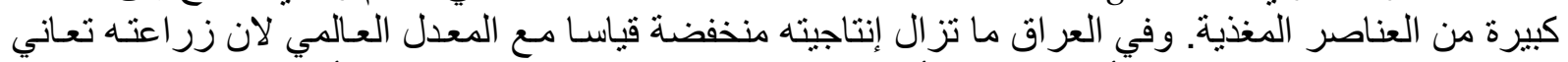

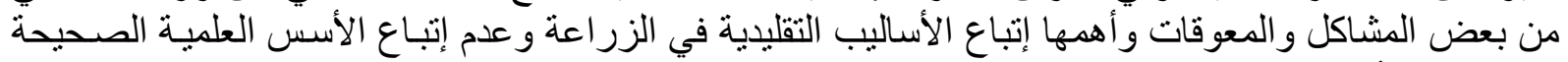

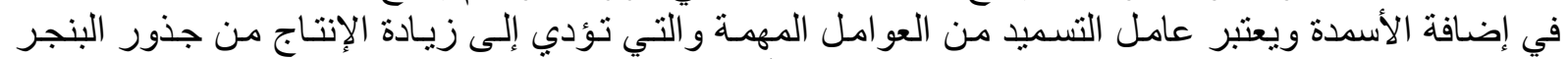

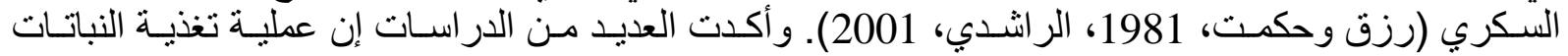

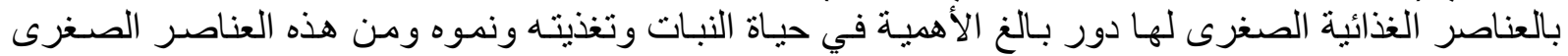

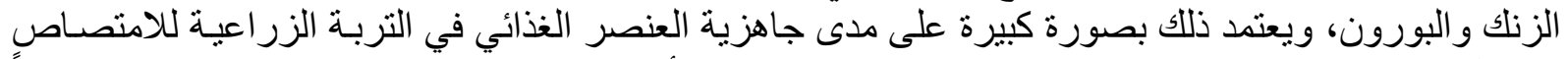

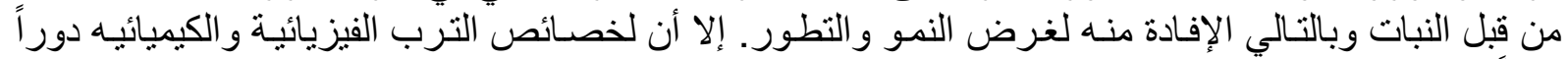

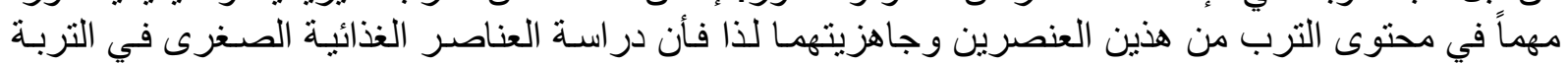

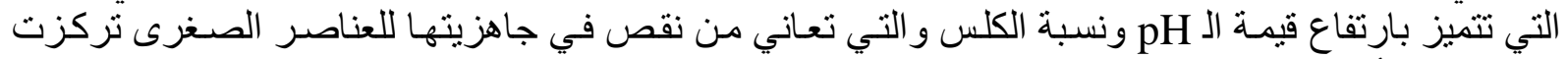

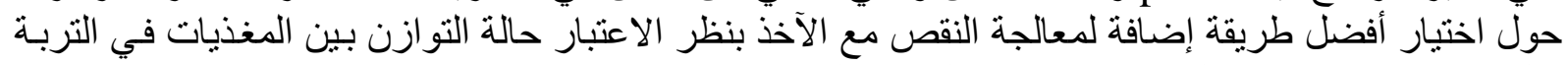

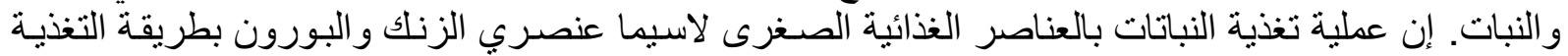

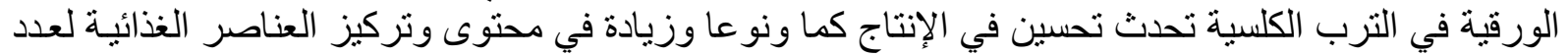

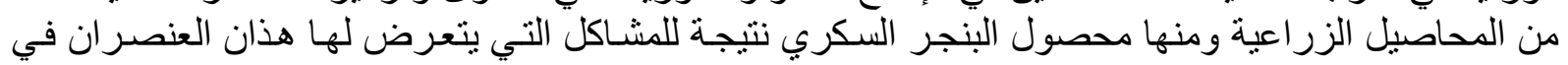

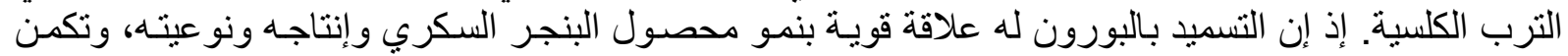

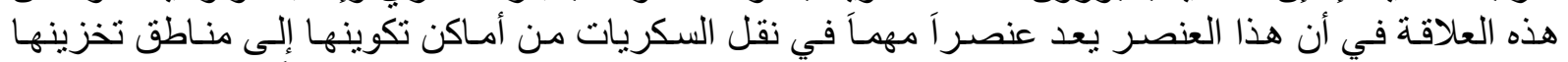

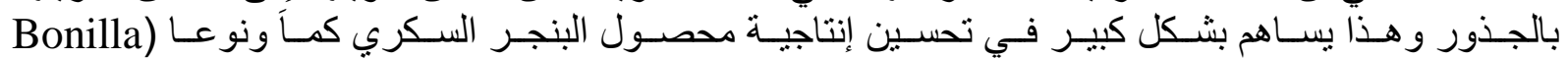

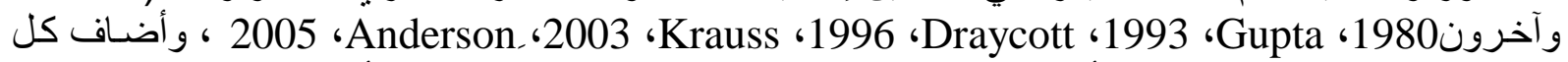

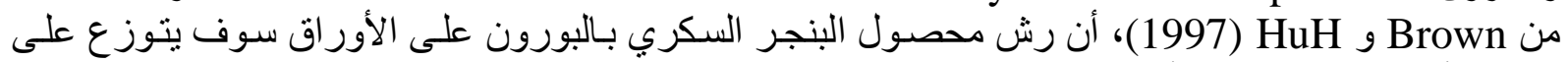

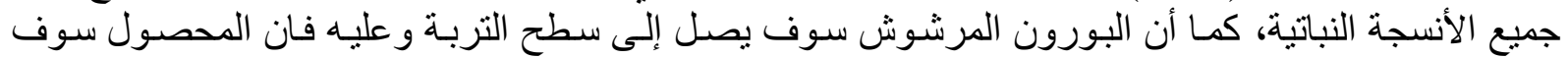

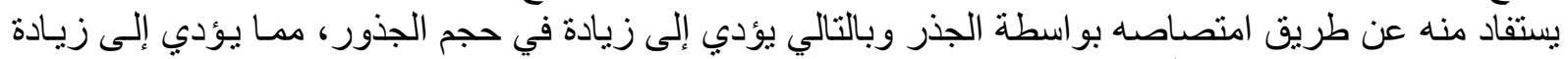

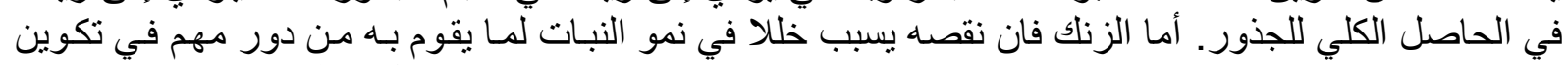

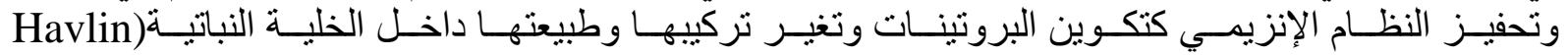

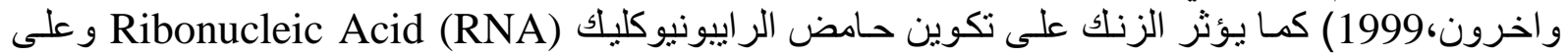


Mesopotamia J. of Agric.

Vol. (45) No. (3) 2017
ISSN: 2224 - 9796 (Online)

ISSN: 1815 - $316 \mathrm{X}$ (Print)

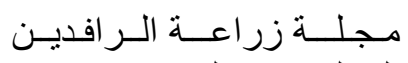

المجلد (45) العدد (3) 2017

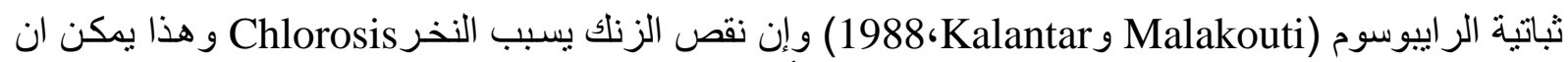
يؤدي مع اشتداد اعر اض النقص الى التيبس او الجفاف أي الموت الموضعي للخلايا (Anonymous، 2004).

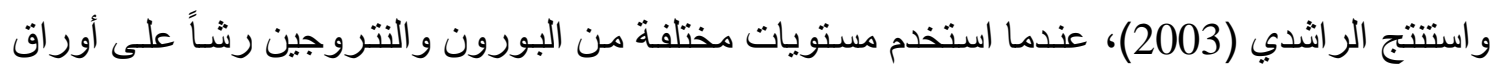

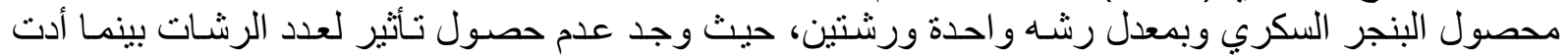

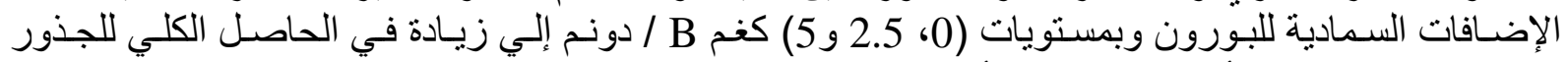

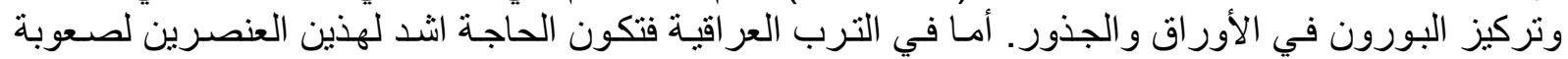

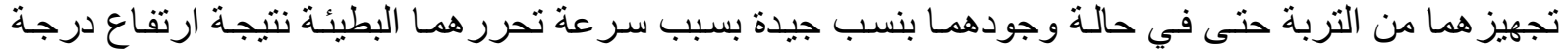

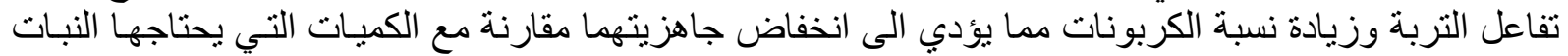

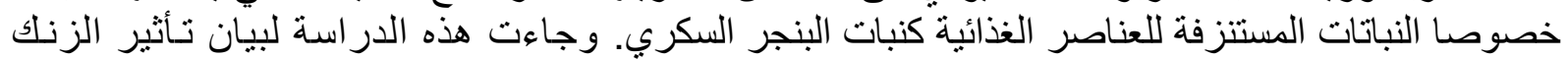

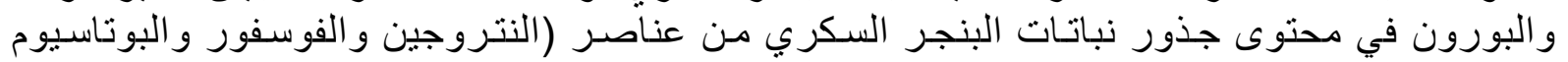

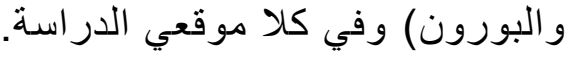

\section{مواد البحث وطر ائقه}

اختيرت تربتين من موقعين في محافظة نينوى ضمن رتبتي Antisols و Aridisols

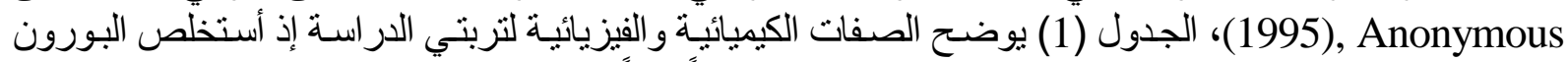

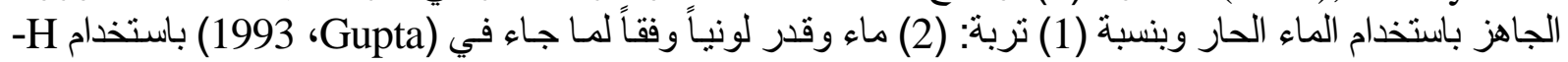

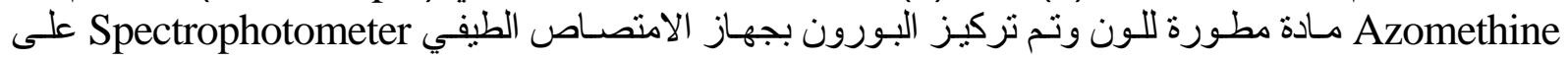
طول موجي

الجدول (1): الصفات الكيميائية والفيزيائية لتربتي الدر اسة. Table (1) Chemical and physical characters of the study soils

\begin{tabular}{|c|c|c|c|}
\hline موقع قبر العبد Entisols & Aridisols موقع الثيخ محمد & \multicolumn{2}{|c|}{ الصفات } \\
\hline 2.91 & 0.66 & \multicolumn{2}{|c|}{ ملوحة التربة EC dS مل } \\
\hline 7.525 & 7.22 & \multicolumn{2}{|c|}{ pH درجة التفاعل pH } \\
\hline 136 & 252 & \multicolumn{2}{|c|}{ كاربونات الكالسيوم g.kg-1 } \\
\hline 10.78 & 9.40 & \multicolumn{2}{|c|}{ المادة العضوية kg.g OM } \\
\hline 52.07 & 38.80 & $\mathrm{~N}$ & \multirow{5}{*}{$\begin{array}{l}\text { Available } \\
\text { content } \\
\text { المحتوى الجاهز } \\
\text { mg.kg }{ }^{-1}\end{array}$} \\
\hline 8.60 & 11.09 & $\mathrm{P}$ & \\
\hline 148 & 109 & $\mathrm{~K}$ & \\
\hline 0.55 & 0.66 & $\mathrm{~B}$ & \\
\hline 0.325 & 0.26 & $\mathrm{Zn}$ & \\
\hline 145 & 141.5 & الرمل sand & \multirow{4}{*}{ 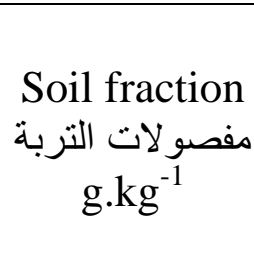 } \\
\hline 460 & 378 & السلت silt & \\
\hline 390 & 480.5 & الطين clay & \\
\hline غرينية S.C.L & طينية clay & Text النسجة & \\
\hline
\end{tabular}

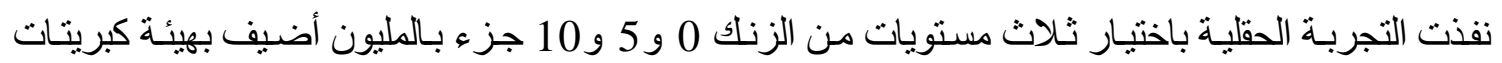

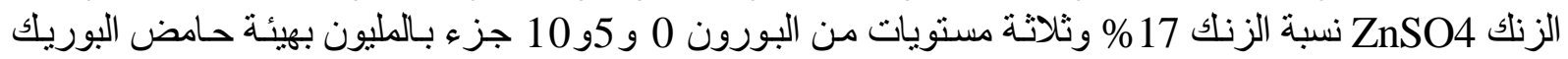
نسبة البورون 17 $17 \mathrm{HO}_{3} \mathrm{BO}_{3}$

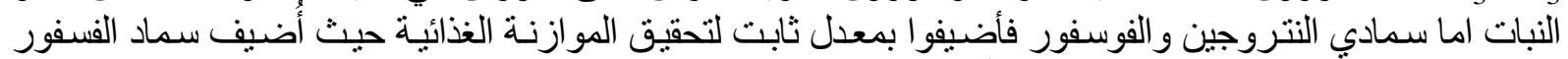

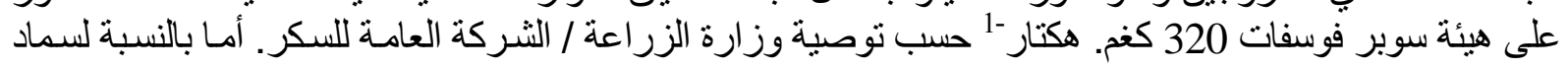




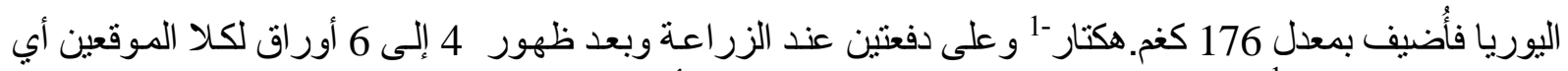

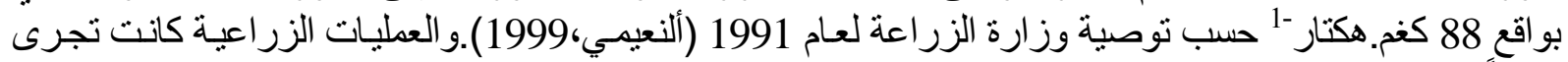

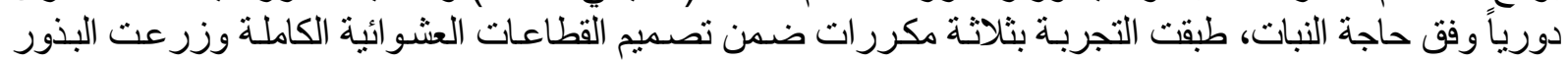

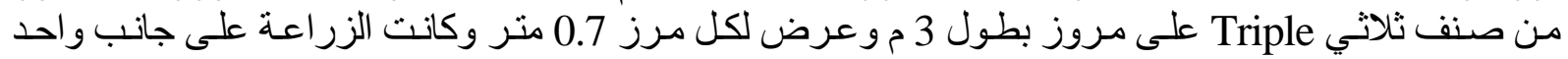

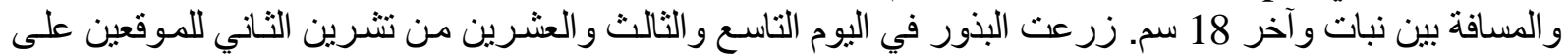

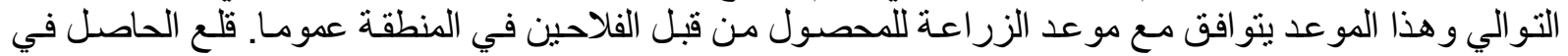

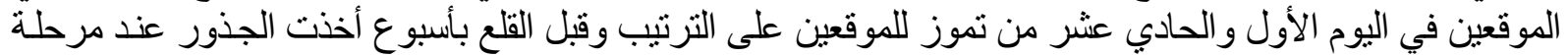

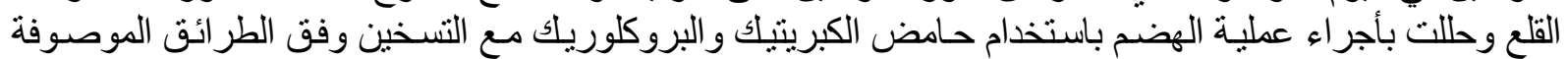

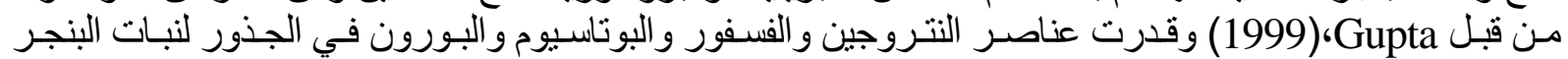

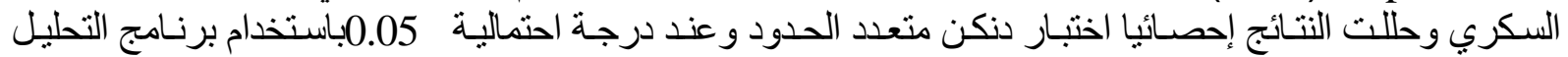

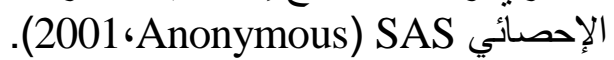

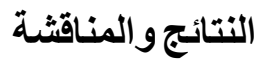

تأثير التغذية الورقية في الأوزان الجافة للجذور (غم / نبات): توضح النتائج في الجدول (2) بـأن زيادة تركيز

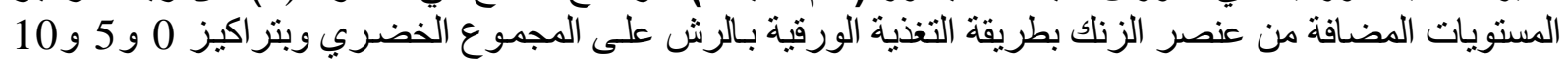

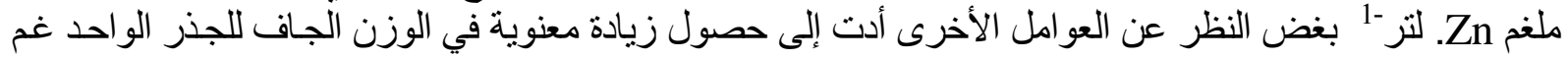

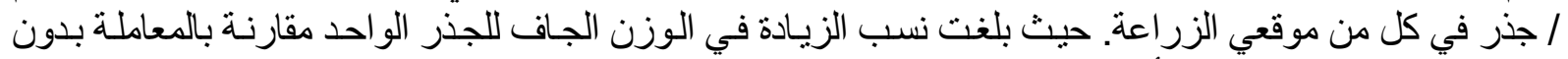

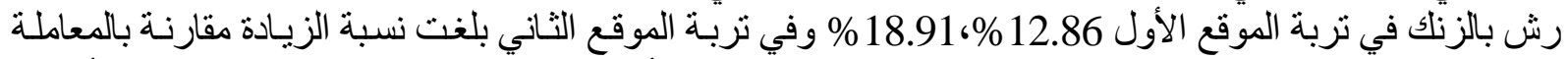

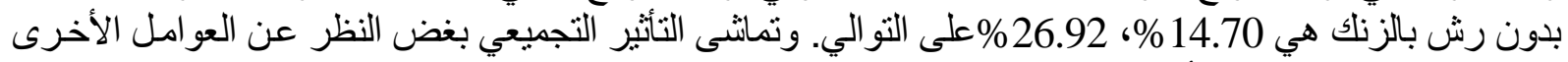

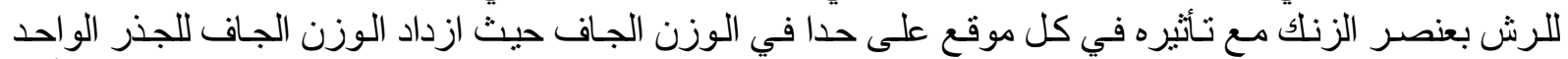

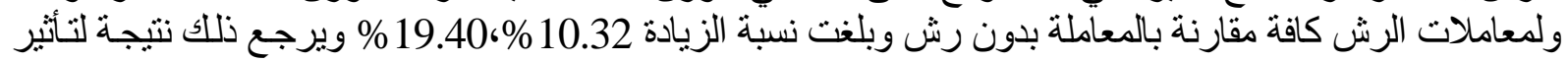

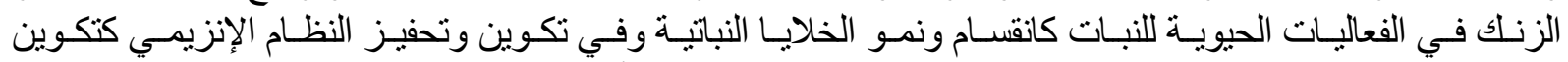

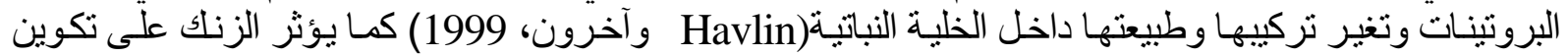

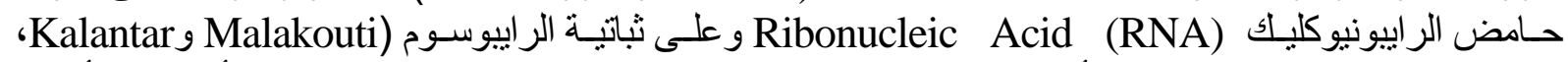

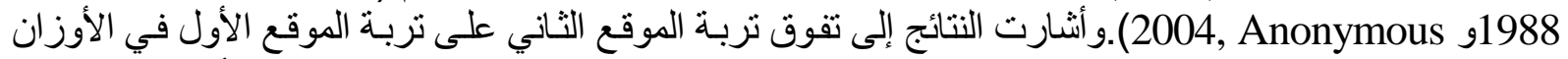

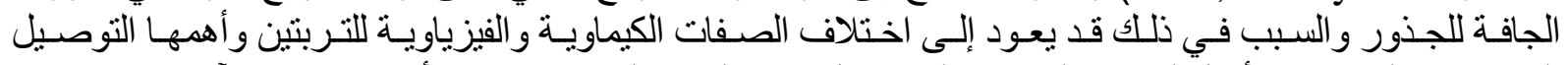

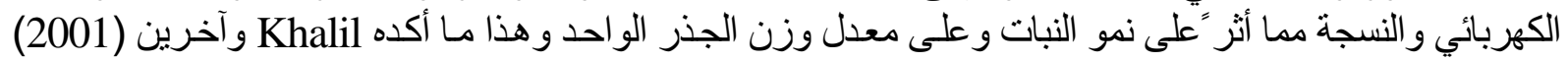

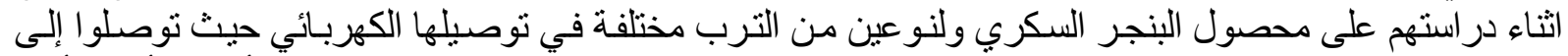

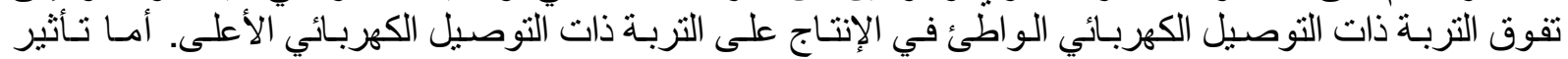

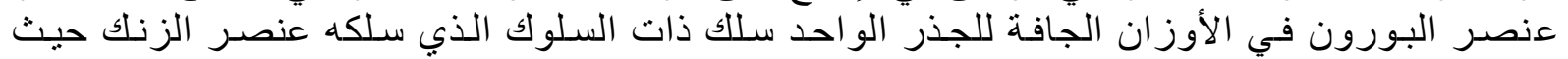

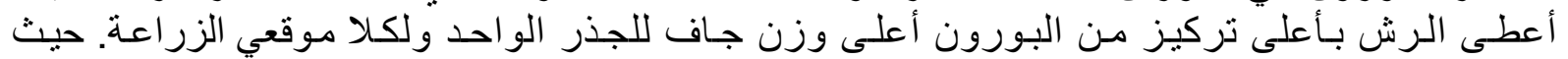

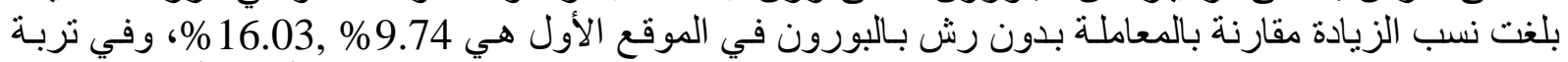

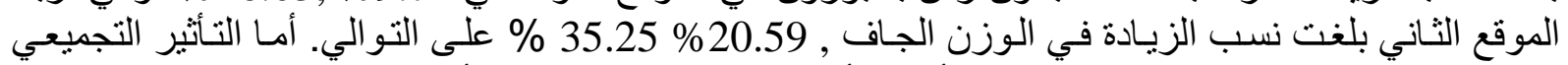

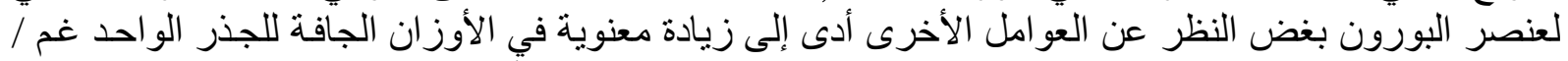

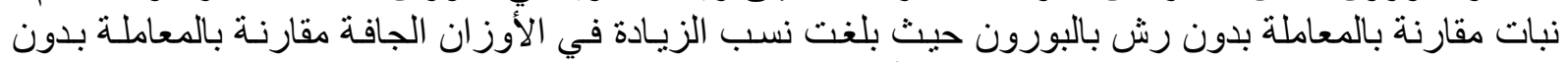

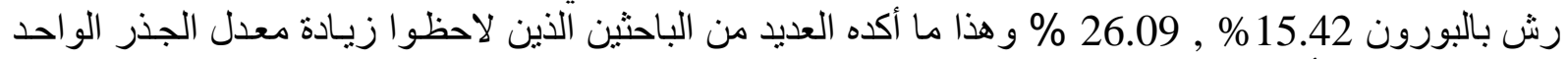

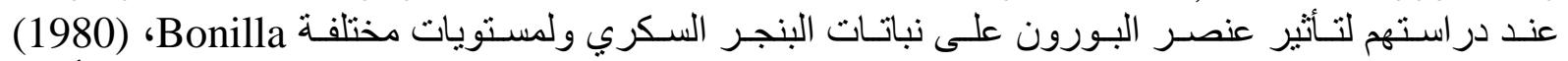

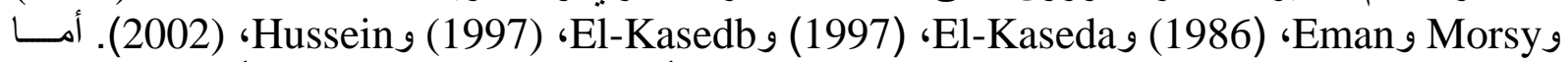

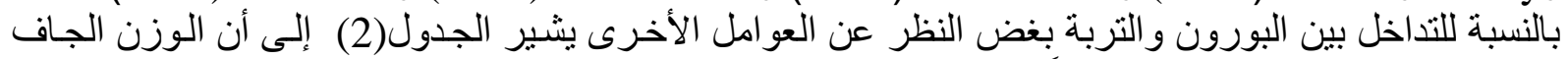

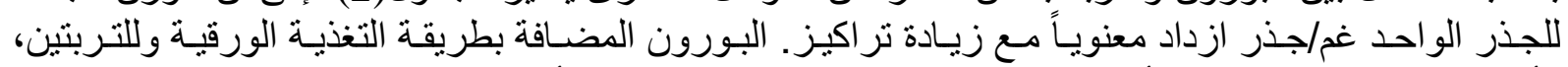

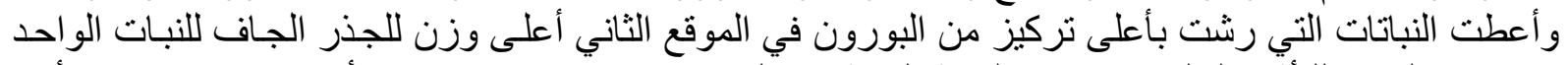

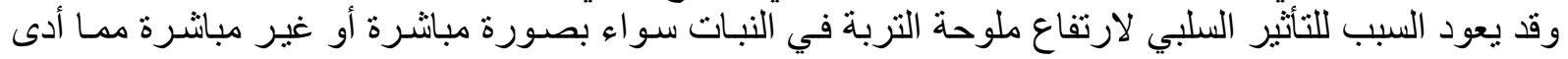

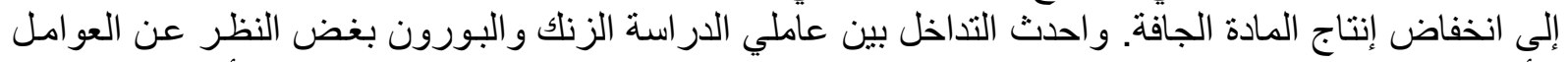

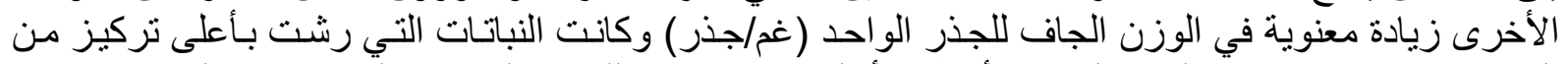

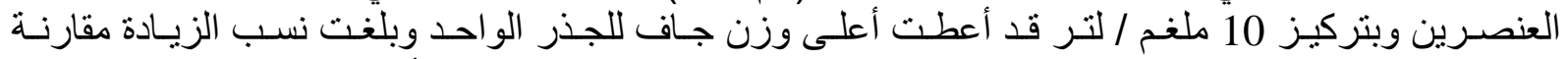

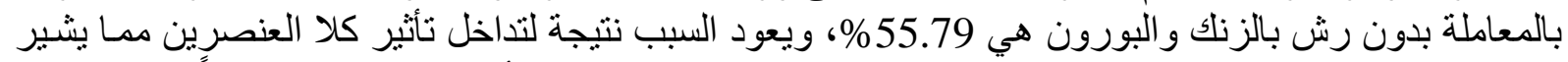

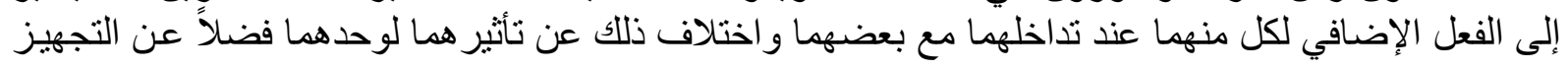


Mesopotamia J. of Agric.

Vol. (45) No. (3) 2017
ISSN: 2224 - 9796 (Online)

ISSN: 1815 - $316 \mathrm{X}$ (Print)

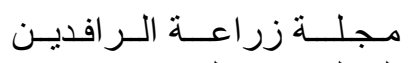

المجلد (45) العدد (3) 2017

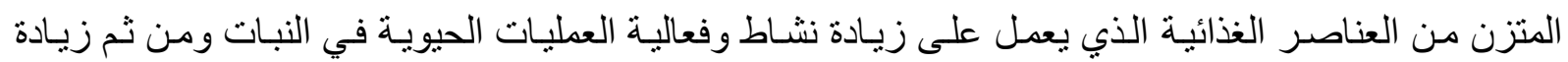

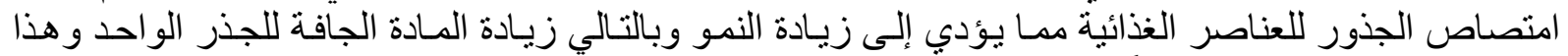

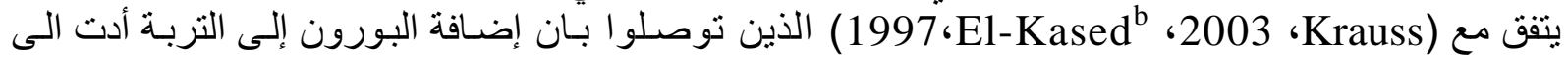

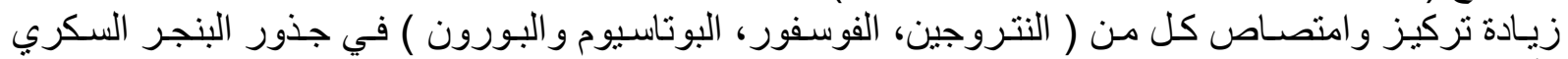

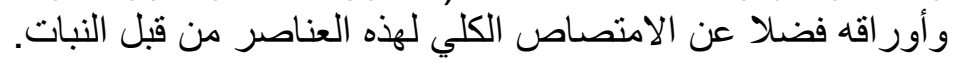

$$
\text { الجدول (2): نأثثير التغذية الورقية بالزنك و البورون في الحاصل الجاف للجذر الواحد غم.نبات-1 }
$$

Table.(2): Effect of zinc and boron foliar application on a dry yield gm.plant ${ }^{-1}$.

\begin{tabular}{|c|c|c|c|c|c|}
\hline \multirow{2}{*}{$\begin{array}{c}\text { تأثثر المواقع } \\
\text { Soil } \\
\text { effect }\end{array}$} & \multirow{2}{*}{$\begin{array}{c}\text { تأثير الزنك } \\
\text { Zinc } \\
\text { effect }\end{array}$} & \multicolumn{3}{|c|}{$\begin{array}{c}\text { تركيز البورون (ملغم/ لتر) } \\
\text { Boron concentration (ppm) }\end{array}$} & \multirow{2}{*}{$\begin{array}{l}\text { تركيز الزنك (ملغم/ لتر) } \\
\text { Zinc conc. (ppm) }\end{array}$} \\
\hline & & 10 & 5 & 0 & \\
\hline & \multicolumn{5}{|c|}{ الموقع الاول تربة المبا } \\
\hline & $168.66 \mathrm{c}$ & 183.33 & 177.66 & 145.00 & 0 \\
\hline & $190.35 \mathrm{~b}$ & 203.33 & 191.18 & 176.53 & 5 \\
\hline & $200.56 \mathrm{a}$ & 211.21 & 196.66 & 193.44 & 10 \\
\hline & & $199.29 \mathrm{a}$ & $188.50 \mathrm{~b}$ & $171.76 \mathrm{c}$ & Boron effect تأثثر البورون \\
\hline & \multicolumn{5}{|c|}{ الموقع الثاني تربة 2nd location Aridisols } \\
\hline & $197.10 \mathrm{c}$ & 212.41 & 203.57 & 175.30 & 0 \\
\hline & $226.09 \mathrm{~b}$ & 267.48 & 230.18 & 180.26 & 5 \\
\hline & $250.16 \mathrm{a}$ & 287.81 & 250.52 & 212.13 & 10 \\
\hline & & $255.94 \mathrm{a}$ & $228.21 \mathrm{~b}$ & $189.23 \mathrm{c}$ & Boron effect تأثثر البورون \\
\hline & \multicolumn{5}{|c|}{ التحليل التجميعي } \\
\hline & $188.74 \mathrm{c}$ & 197.87 & 190.615 & 160.15 & 0 \\
\hline & $208.22 \mathrm{~b}$ & 235.405 & 210.68 & 178.395 & 5 \\
\hline $186.52 \mathrm{~b}$ & $225.36 \mathrm{a}$ & 249.51 & 223.59 & 202.785 & 10 \\
\hline $224.44 \mathrm{a}$ & & $227.60 \mathrm{a}$ & $208.35 b$ & $.180 .50 \mathrm{c}$ & Boron effect تأثثر البورون \\
\hline
\end{tabular}

الأحرف المتثابهة ضمن العمود أو الصف الو احد لا تختلف فيما بينها معنويا حسب اختبار دنكن وتحت بمستوى احتمال 5\%

Values with in columns or rows followed by the same letters are not significantly at $p=5 \%$

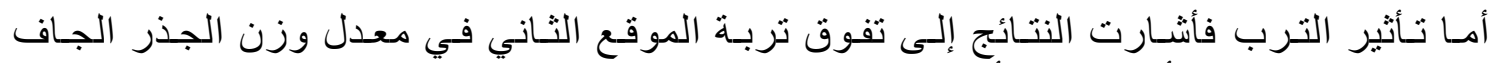

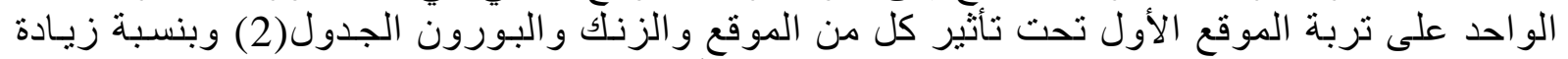

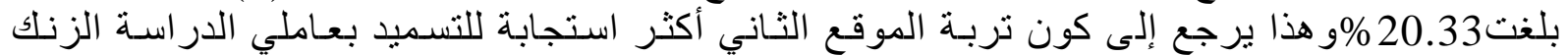

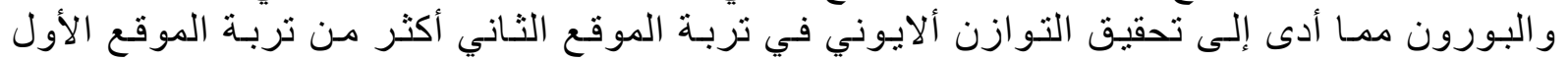

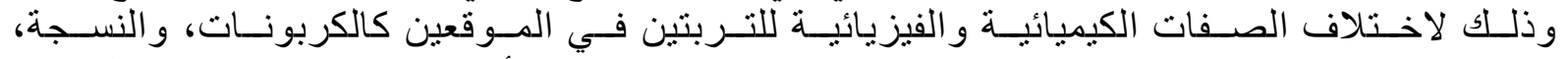

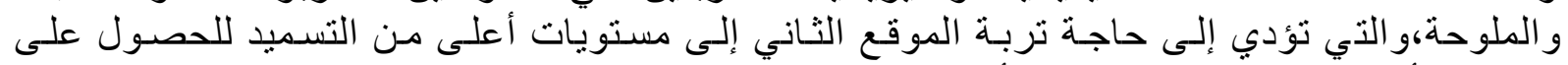

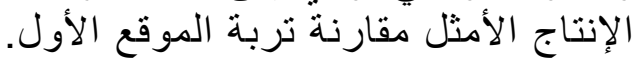

التغذية الورقية ومحتوى البورون في الجذور (مسايكرو غرام. نبات-1):- تشير النتائج في الجدول (3)

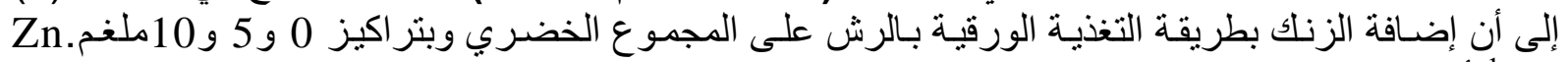

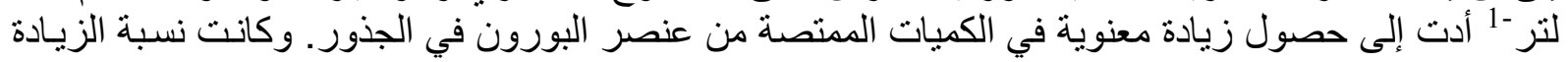

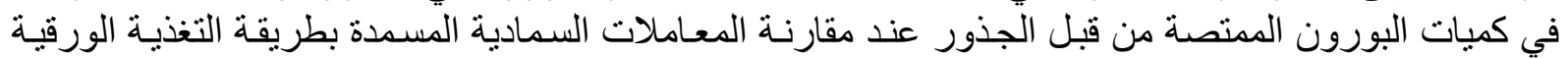


Mesopotamia J. of Agric.

Vol. (45) No. (3) 2017
ISSN: 2224 - 9796 (Online)

ISSN: 1815 - 316 X (Print)

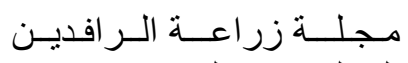

المجلد (45) العدد (3) 2017

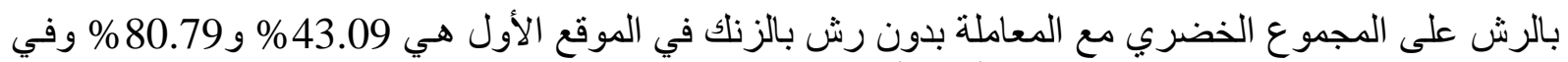

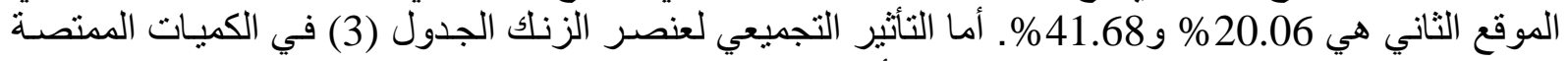

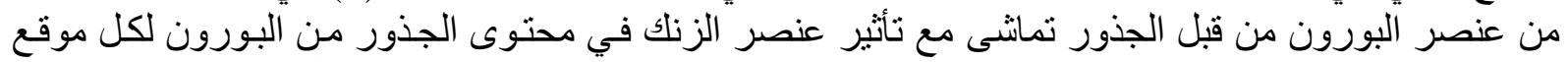

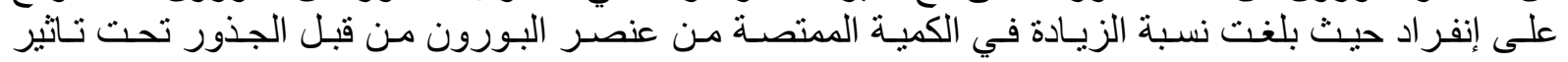

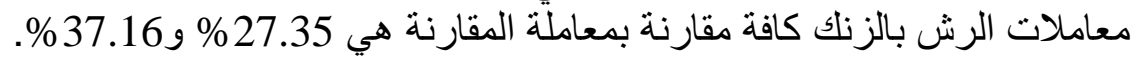

الجدول (3) تأثير التغذية الورقية بالزنك والبورون في محتوى البورون مايكروغرام.نبات-1 Table (3): Effect of zinc and boron folier application on boron content $\mu$ gm.plant ${ }^{-1}$.

\begin{tabular}{|c|c|c|c|c|c|}
\hline \multirow{2}{*}{$\begin{array}{c}\text { تأثنير المواقع } \\
\text { Soil } \\
\text { effect }\end{array}$} & \multirow{2}{*}{$\begin{array}{c}\text { تأثير الزنك } \\
\text { Zinc } \\
\text { effect }\end{array}$} & \multicolumn{3}{|c|}{$\begin{array}{c}\text { تركيز البورون (ملغم/ لتر) } \\
\text { Boron concentration (ppm) }\end{array}$} & \multirow{2}{*}{$\begin{array}{l}\text { تركيز الزنك (ملغم/ لتر) } \\
\text { Zinc conc. (ppm) }\end{array}$} \\
\hline & & 10 & 5 & 0 & \\
\hline & \multicolumn{5}{|c|}{ الموقع الاول تربة location Entisols } \\
\hline & $2740.0 \mathrm{c}$ & 3541.56 & 3037.33 & 1641.0 & 0 \\
\hline & $3920.6 \mathrm{~b}$ & 4680.0 & 3832.07 & 3249.85 & 5 \\
\hline & $4953.8 \mathrm{a}$ & 6008.04 & 4456.66 & 4396.73 & 10 \\
\hline & & $4743.2 \mathrm{a}$ & $37.75 .4 \mathrm{~b}$ & $3095.9 \mathrm{~b}$ & Boron effect تأثير البورون \\
\hline & \multicolumn{5}{|c|}{ الموقع الثاني تربة location Aridisols } \\
\hline & $5902.1 \mathrm{c}$ & 6980.95 & 6518.21 & 4207.20 & 0 \\
\hline & $7085.2 \mathrm{~b}$ & 9559.17 & 7453.46 & 4242.89 & 5 \\
\hline & $8362.3 \mathrm{a}$ & 10761.1 & 8170.25 & 6155.62 & 10 \\
\hline & & $9100.4 \mathrm{a}$ & $7380.6 \mathrm{~b}$ & $4868.6 \mathrm{c}$ & Boron effect تأثثر البورون \\
\hline & \multicolumn{5}{|c|}{ التحليل التجميعي Accumulative analysis } \\
\hline & $4321.1 \mathrm{~b}$ & 5261.25 & 4777.77 & 2924.1 & 0 \\
\hline & $5502.9 \mathrm{a}$ & 7119.58 & 5642.76 & 3746.37 & 5 \\
\hline $3871.5 \mathrm{~b}$ & $5926.7 \mathrm{a}$ & 6190.41 & 6313.45 & 5276.175 & 10 \\
\hline $7116.5 \mathrm{a}$ & & $6921.8 \mathrm{a}$ & $5578.0 \mathrm{~b}$ & $3982.2 \mathrm{c}$ & Boron effect تأثير البورون \\
\hline
\end{tabular}

الأحرف المتثابهة ضمن العمود أو الصف الو احد لا تختلف فيما بينها معنويا حسب اختبار دنكن وتحت بمستوى احتمال 5\%

Values with in columns or rows followed by the same letters are not significantly at $p=5 \%$

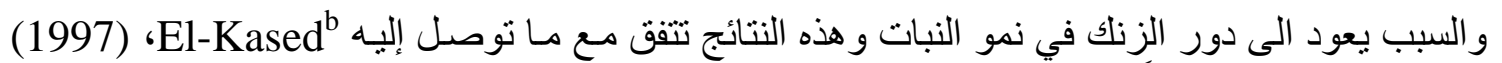

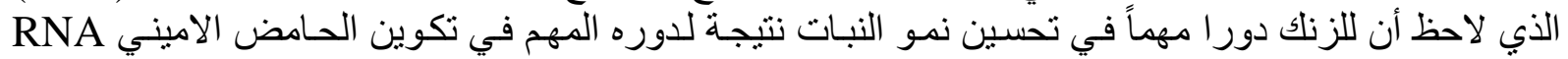

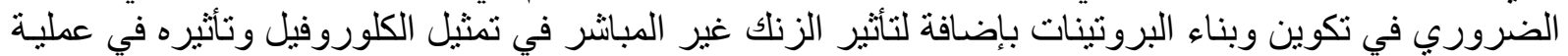

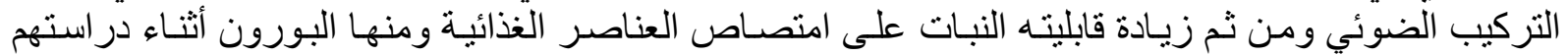

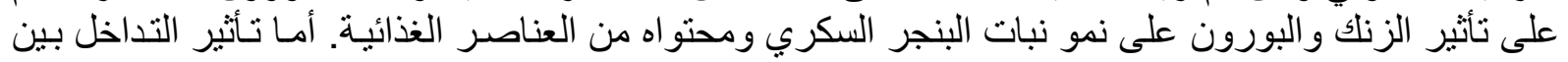

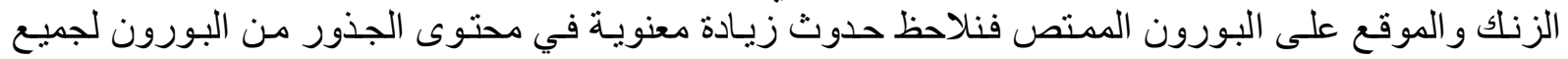

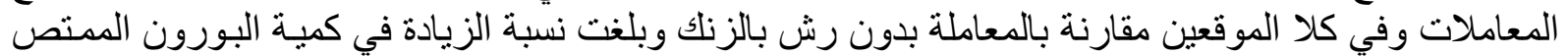

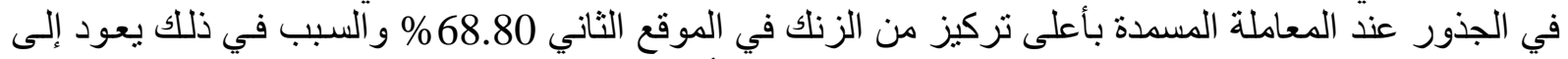

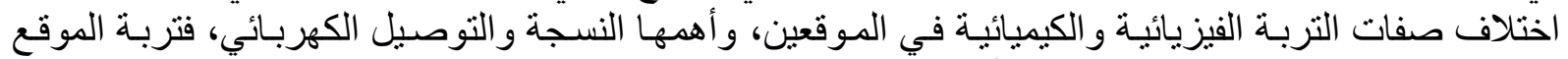

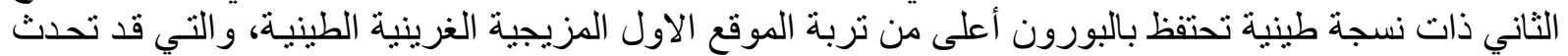

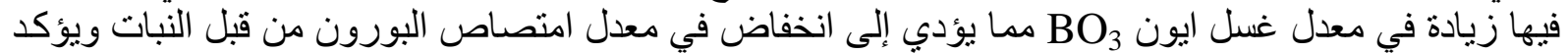

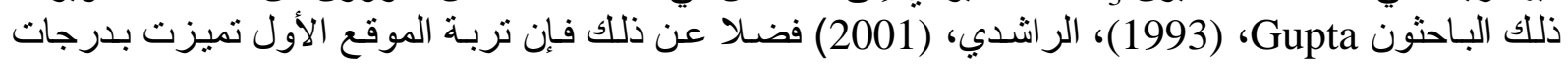




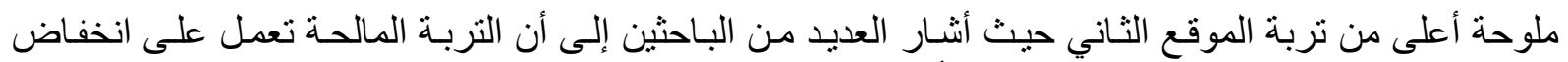

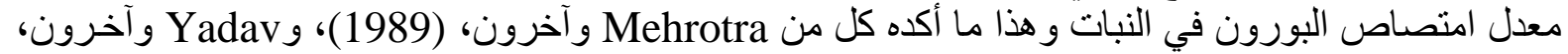

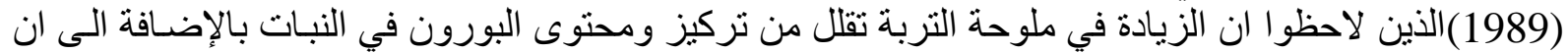

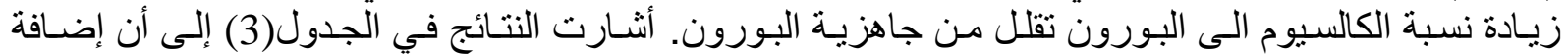

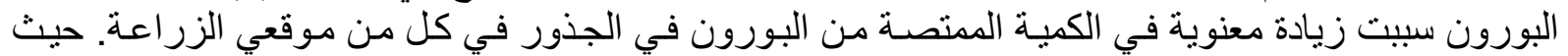

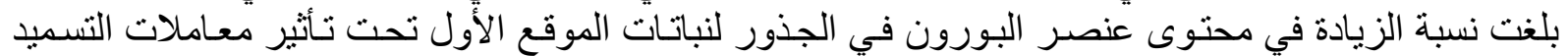

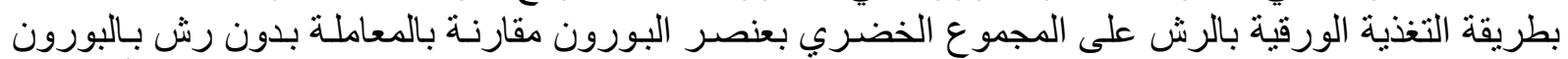

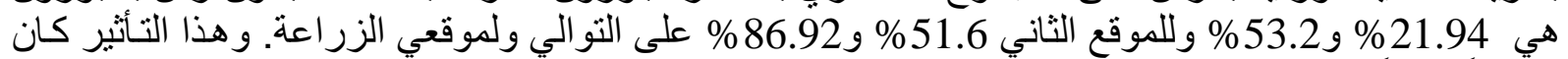

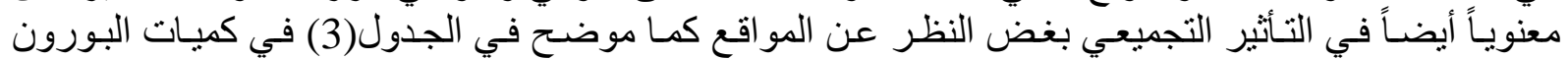

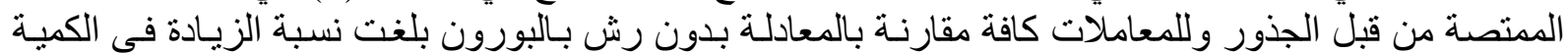

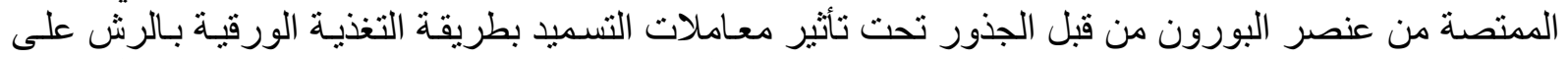

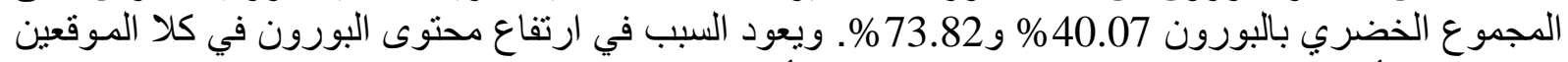

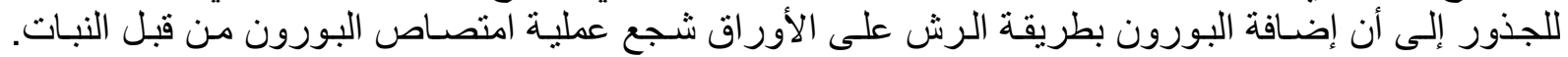

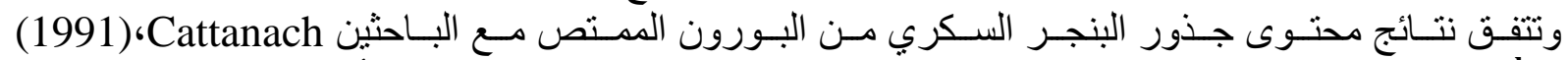

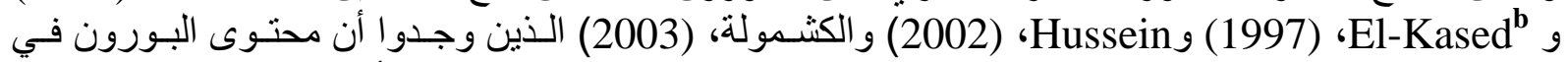

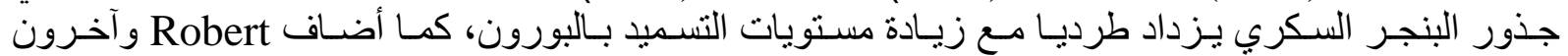

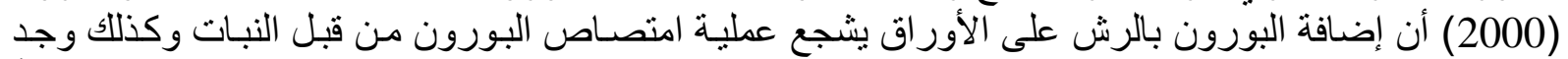

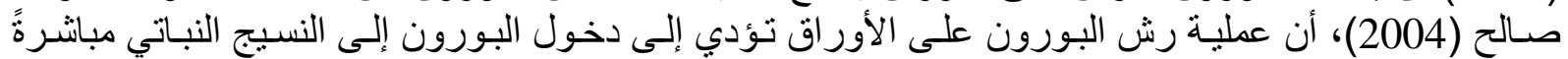

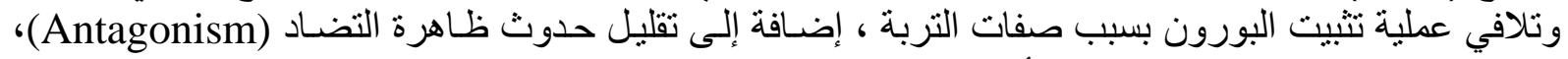

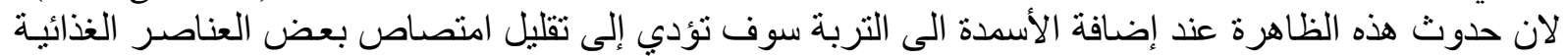

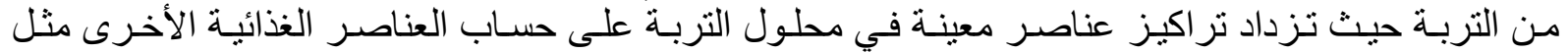

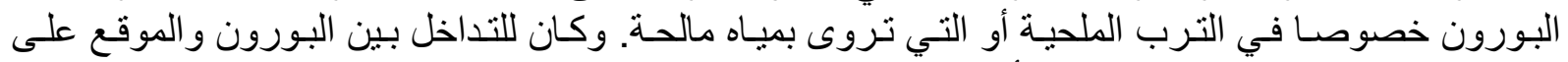

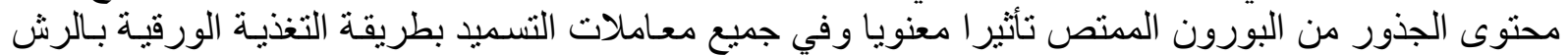

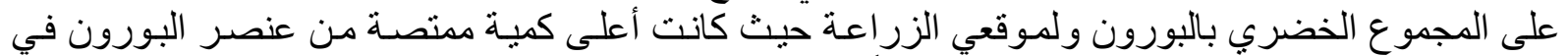

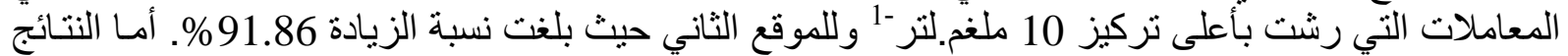

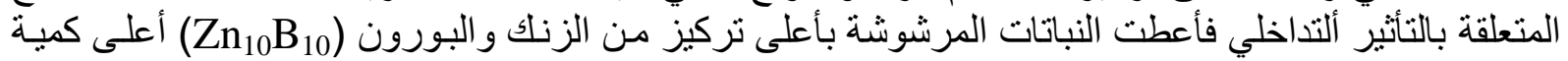

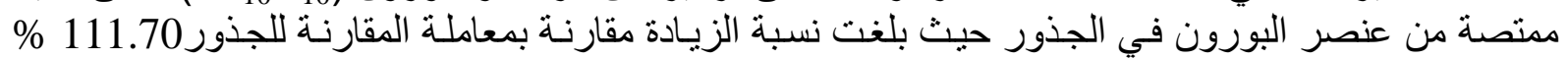

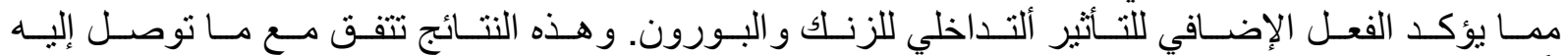
El-Kased

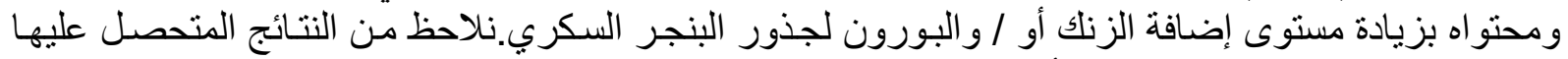

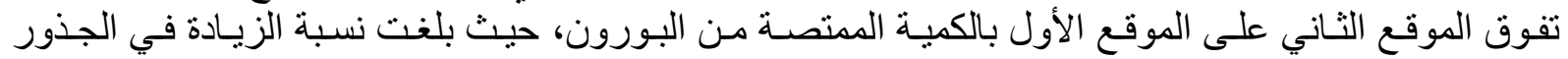
83.81\%، و هذه الزيادة ربما تعزى إلى اختلاف النسجة ودرجة التوصيل الكهربائي و الغسل لكلا الترتيبين وهذا لتها

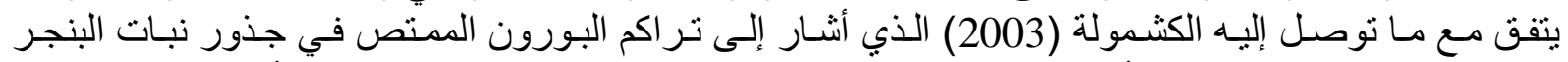

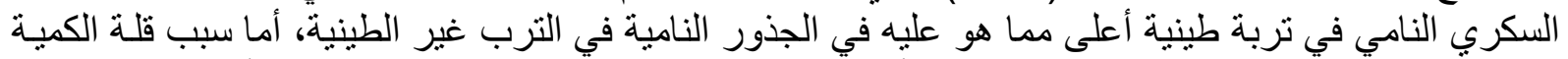

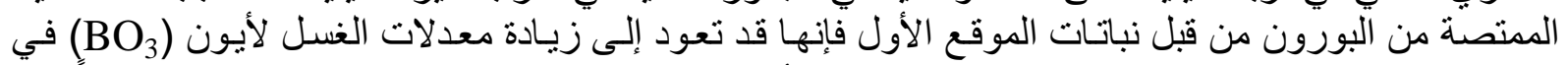

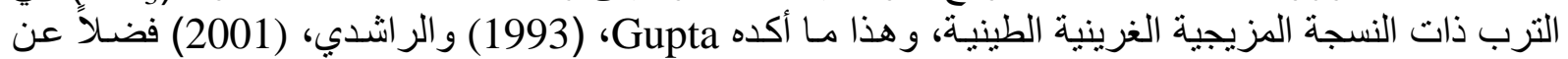

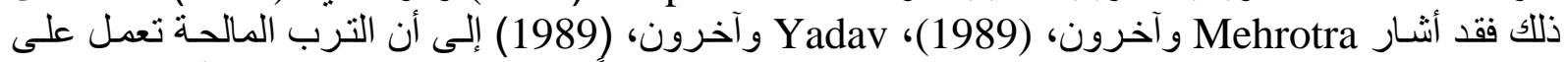

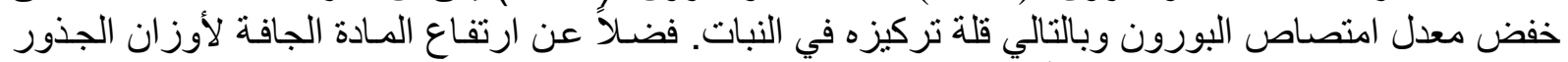

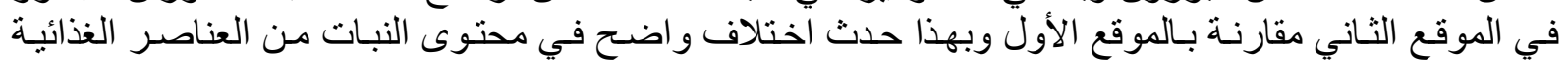
باختنلاف الموقع.

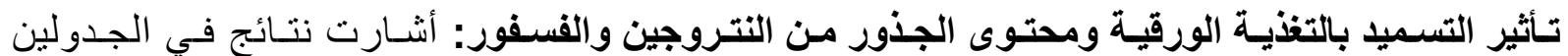

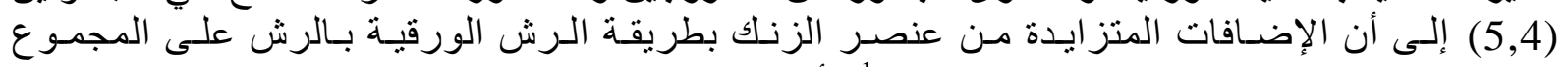

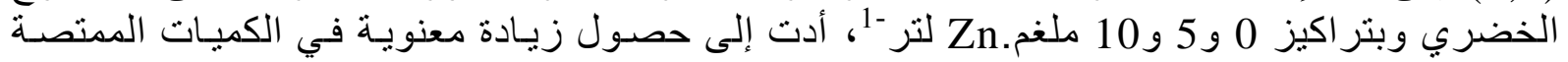

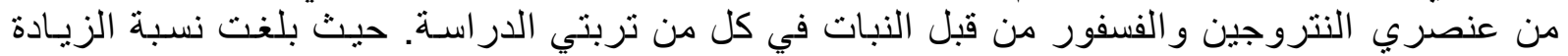

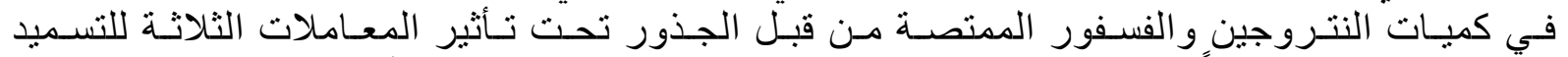

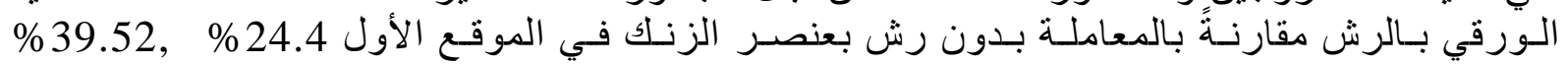


Mesopotamia J. of Agric.

Vol. (45) No. (3) 2017
ISSN: 2224 - 9796 (Online)

ISSN: 1815 - $316 \mathrm{X}$ (Print)

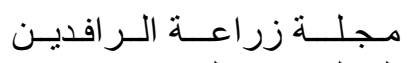

المجلد (45) العدد (3) 2017

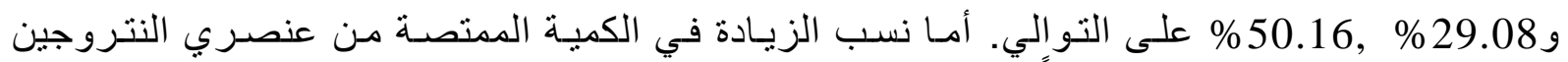

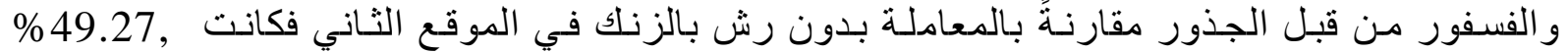

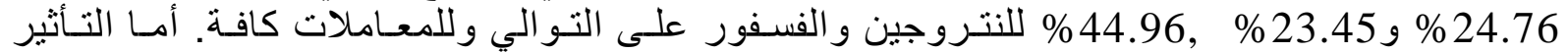

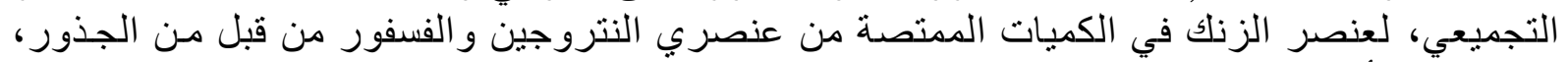

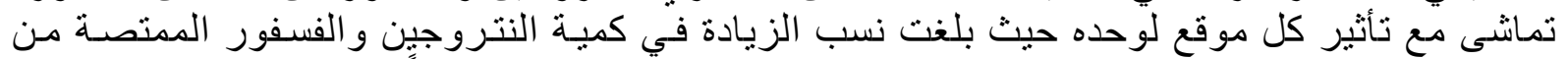

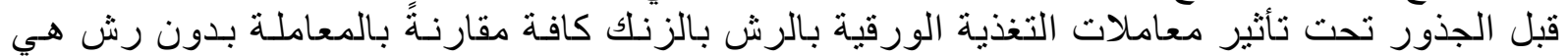

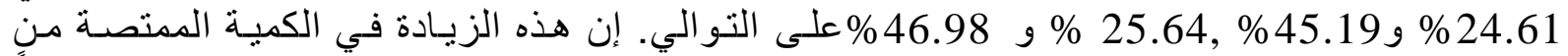

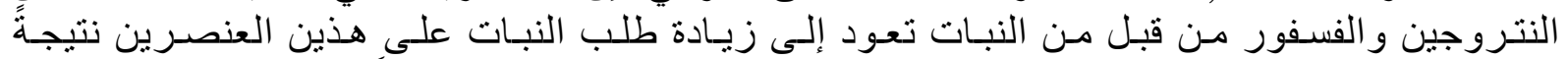

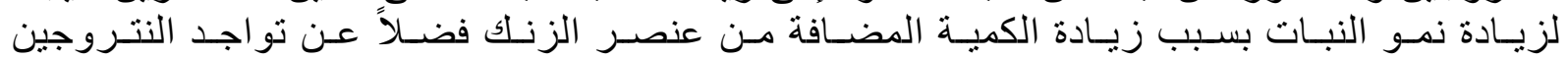

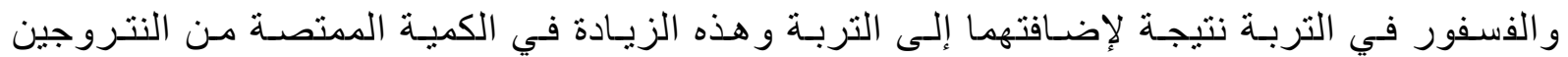

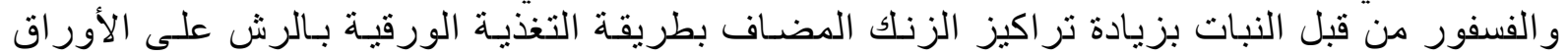

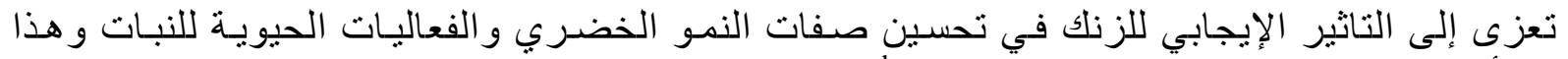

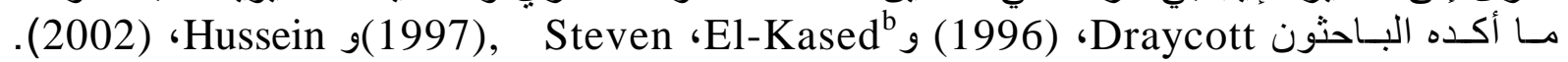

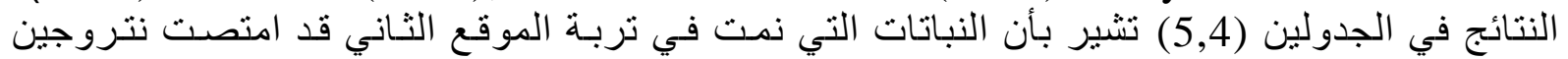

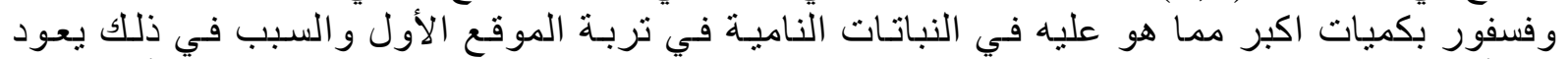

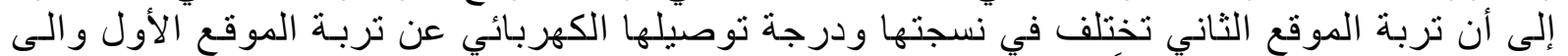

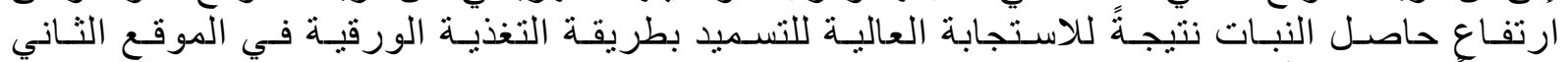

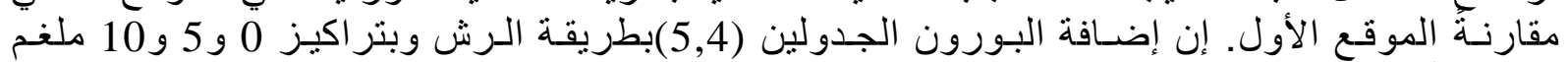

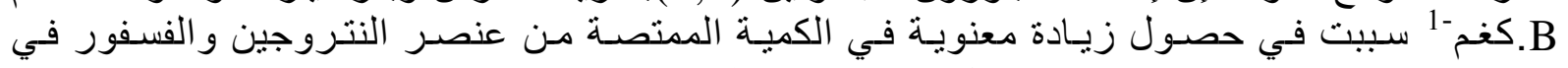

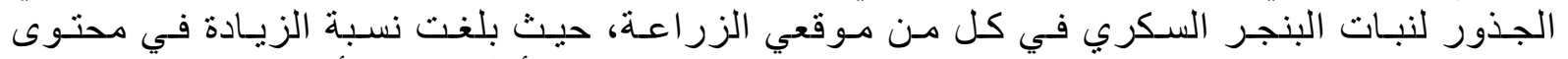

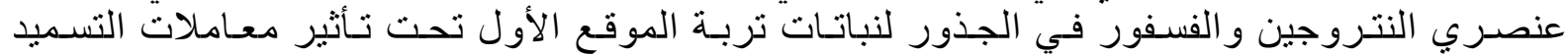

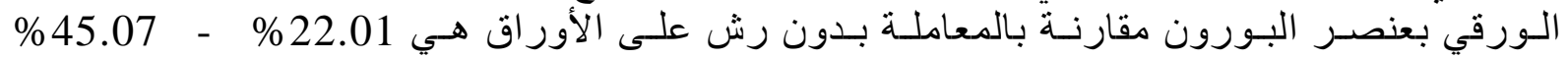

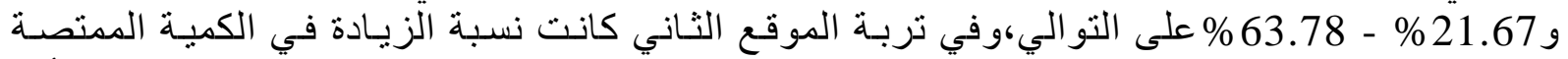
من النتروجين و الفسفور من قبل الجذور هي 837.49\% و

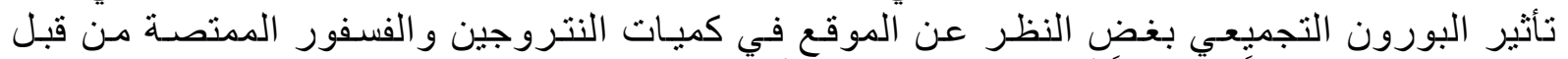

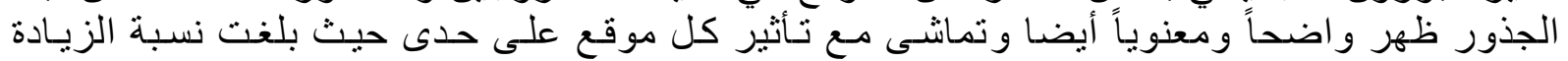

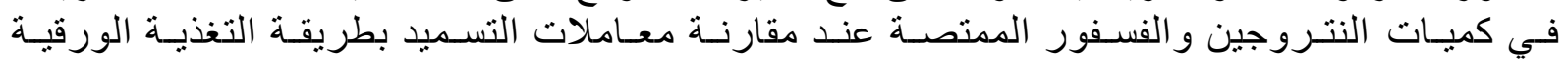

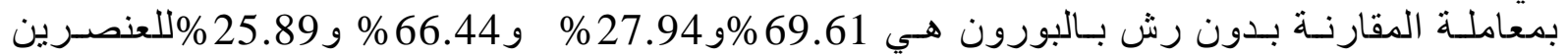
على التو الي.

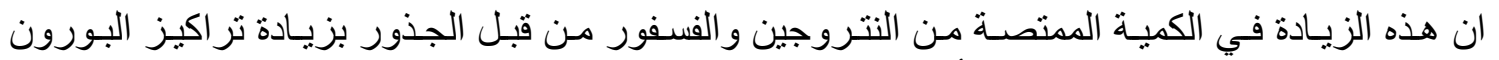

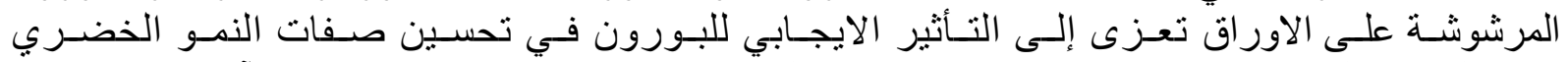

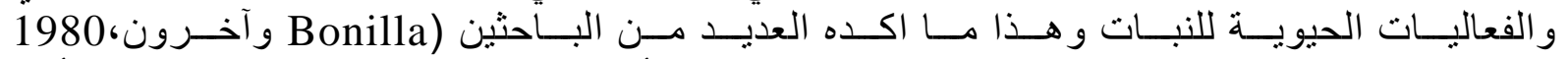

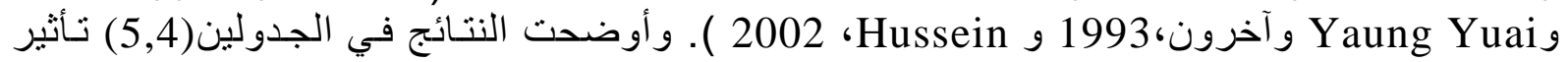

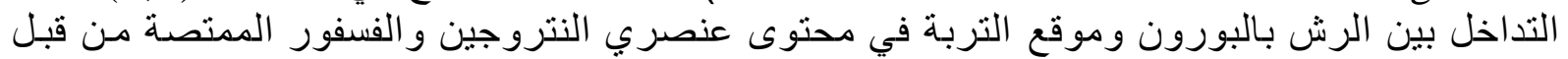

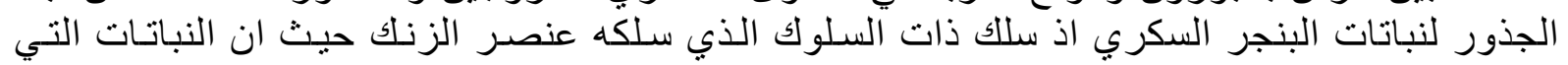

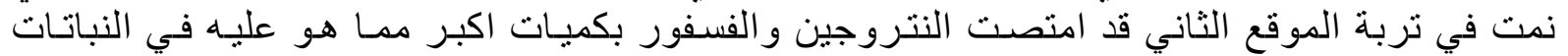

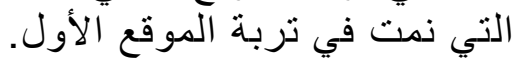

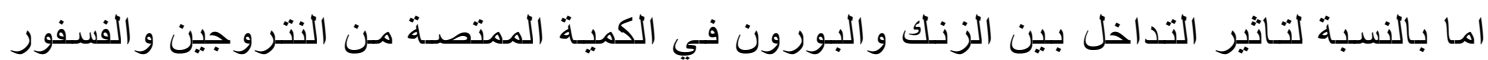

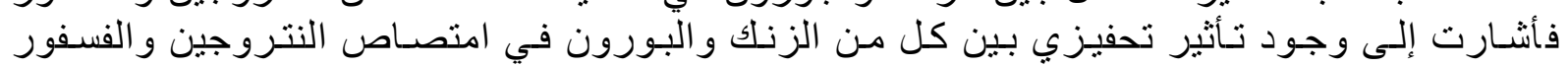

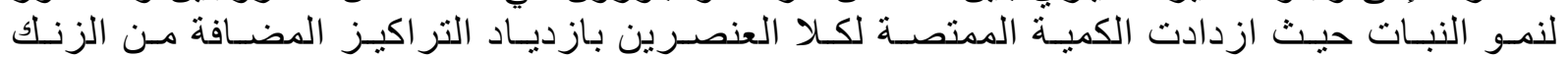

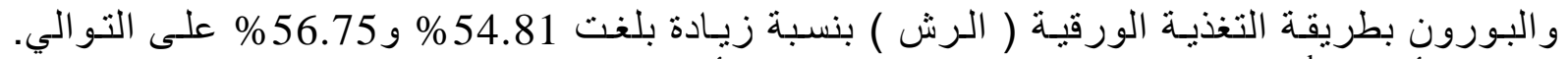

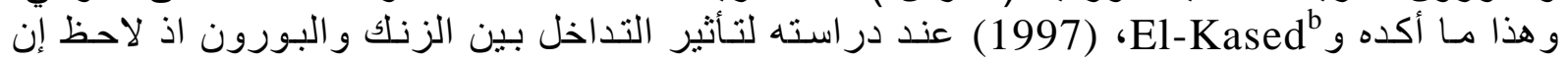

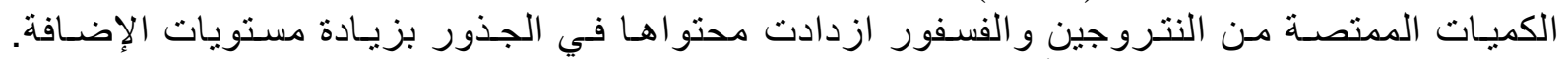

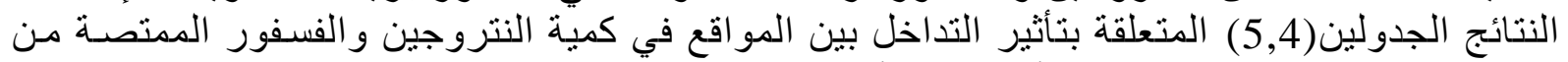

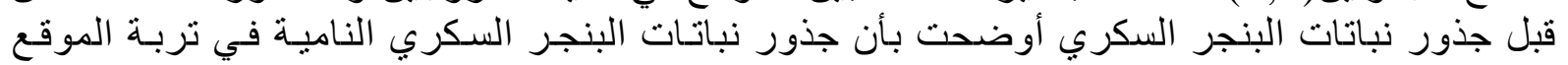


Mesopotamia J. of Agric.

Vol. (45) No. (3) 2017
ISSN: 2224 - 9796 (Online)

ISSN: 1815 - $316 \mathrm{X}$ (Print)

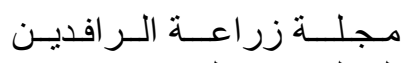

المجلد (45) العدد (3) 2017

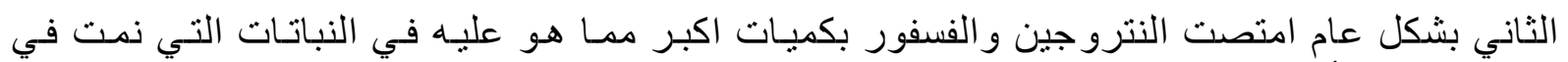

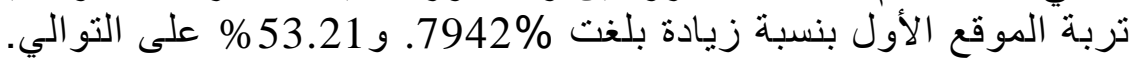

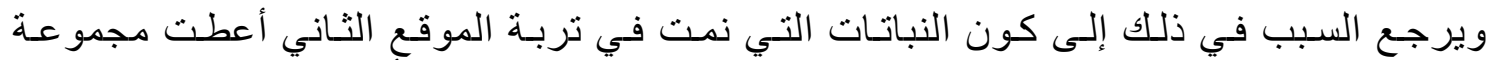

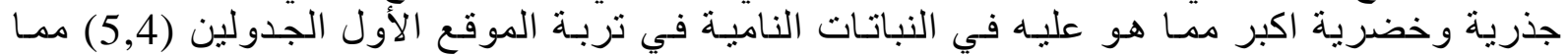

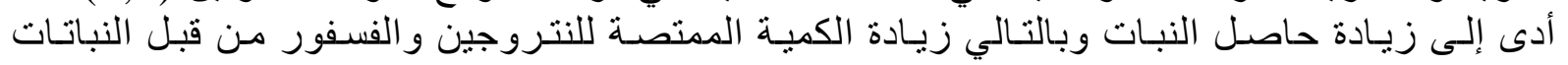

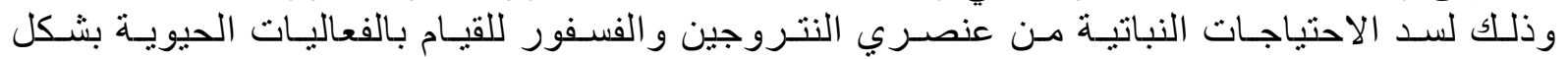

الجدول (4) نأثنير التغذية الورقية بالزنك و البورون في محتوى النتروجين ملغم.نبات-1 Table.(4): Effect of zinc and boron foliar application on nitrogen content mg.plant ${ }^{-1}$.

\begin{tabular}{|c|c|c|c|c|c|}
\hline \multirow{2}{*}{$\begin{array}{c}\text { تأثثير } \\
\text { المع } \\
\text { Soil } \\
\text { effect } \\
\end{array}$} & \multirow{2}{*}{$\begin{array}{c}\text { تأثير الزنك } \\
\text { Zinc } \\
\text { effect }\end{array}$} & \multicolumn{3}{|c|}{$\begin{array}{c}\text { تركيز البورون (ملغم/ لتر) } \\
\text { Boron concentration (ppm) }\end{array}$} & \multirow{2}{*}{$\begin{array}{l}\text { تركيز الزناك (ملغم/ لتر) } \\
\text { Zinc conc. (ppm) }\end{array}$} \\
\hline & & 10 & 5 & 0 & \\
\hline & \multicolumn{5}{|c|}{ الموقع الاول تربة ابة location Entisols } \\
\hline & $1208.96 \mathrm{c}$ & 1357.53 & 1284.20 & 985.15 & 0 \\
\hline & $1503.98 \mathrm{~b}$ & 1746.66 & 1529.50 & 1235.75 & 5 \\
\hline & $1686.75 \mathrm{a}$ & 2112.19 & 1573.33 & 1374.71 & 10 \\
\hline & & $1738.80 \mathrm{a}$ & $1462.35 b$ & $1198.54 \mathrm{c}$ & Boron effect تأثثر البورون \\
\hline & \multicolumn{5}{|c|}{ الموقع الثاني تربة المابة } \\
\hline & $1679.70 \mathrm{c}$ & 2122.61 & 1601.64 & 1314.75 & 0 \\
\hline & $2095.60 \mathrm{~b}$ & 2860.35 & 2028.59 & 1411.88 & 5 \\
\hline & $2507.40 \mathrm{a}$ & 3444.38 & 2364.60 & 1713.5 & 10 \\
\hline & & $2804.50 \mathrm{a}$ & $1998.30 b$ & $1480.00 \mathrm{c}$ & Boron effect تأثثر البورون \\
\hline & \multicolumn{5}{|c|}{ التحليل التجميعي Accumulative analysis } \\
\hline & $1444.30 \mathrm{a}$ & 1740.07 & 1442.92 & 1149.95 & 0 \\
\hline & $1799.80 \mathrm{~b}$ & 2296.50 & 1779.04 & 1323.81 & 5 \\
\hline $1466.6 \mathrm{~b}$ & $2097.10 \mathrm{a}$ & 2778.28 & 1968.96 & 1544.10 & 10 \\
\hline $2094.3 \mathrm{a}$ & & $2271.60 \mathrm{a}$ & $1730.30 \mathrm{~b}$ & $1339.30 \mathrm{c}$ & Boron effect تأثير البورون \\
\hline
\end{tabular}

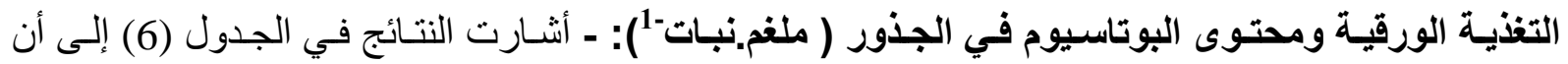

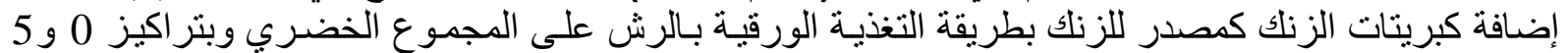

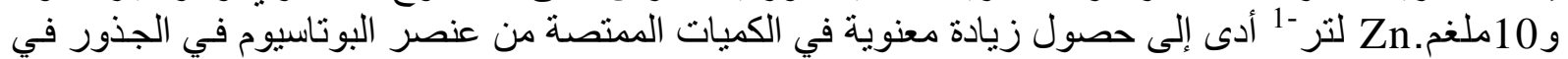

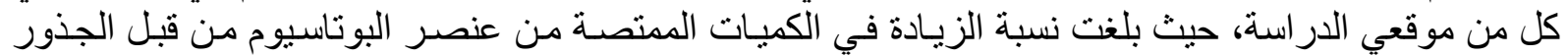

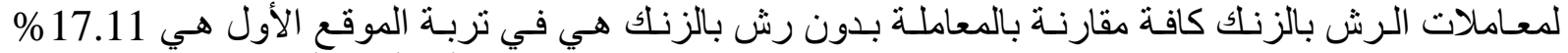

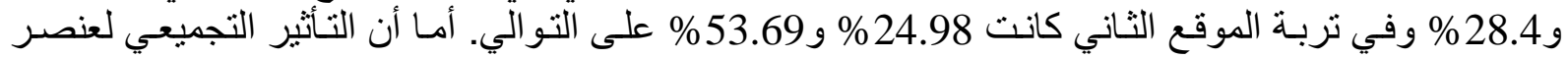

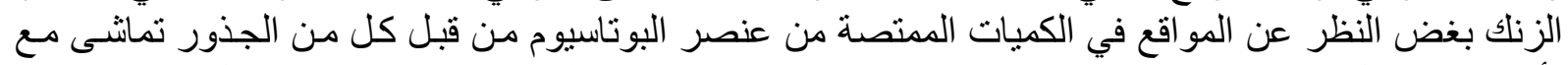

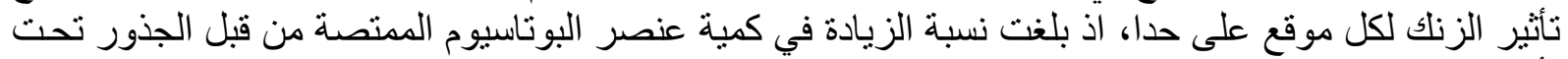

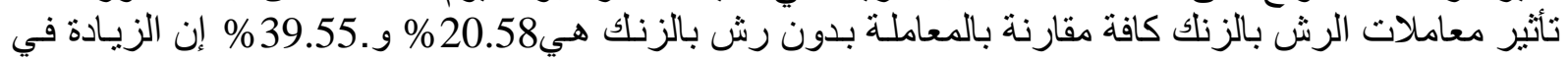

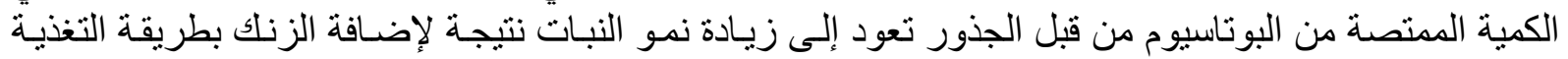

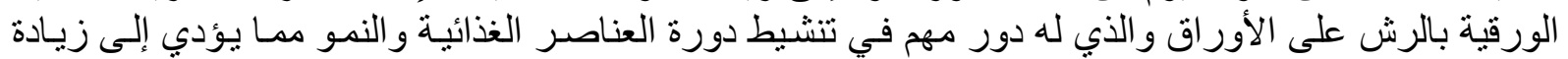


Mesopotamia J. of Agric.

Vol. (45) No. (3) 2017
ISSN: 2224 - 9796 (Online)

ISSN: 1815 - 316 X (Print)

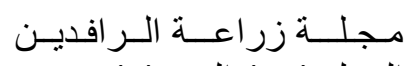

المجلد (45) العدد (3) 2017

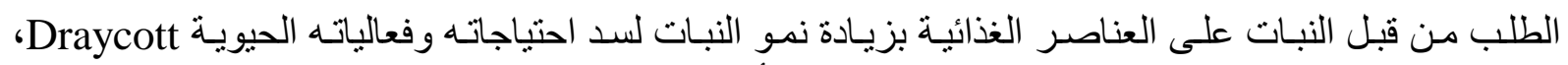

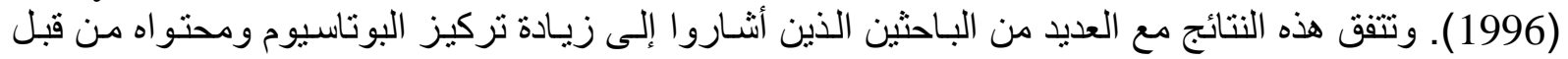

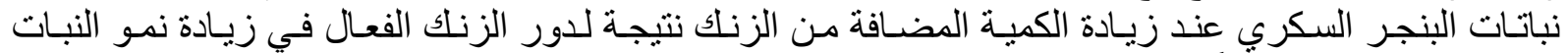
1997 Steven ،El-Kased " 1996 ،Draycott)

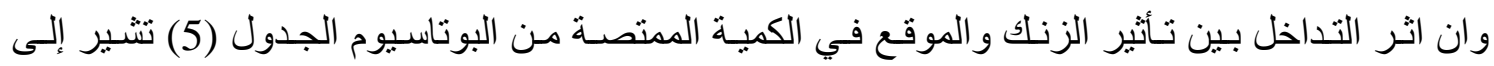

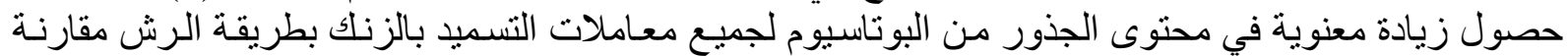

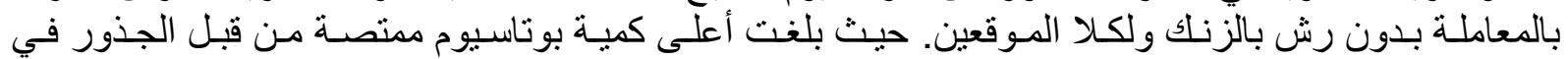

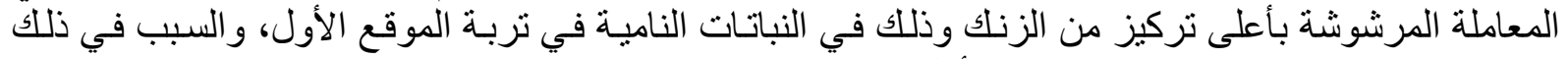

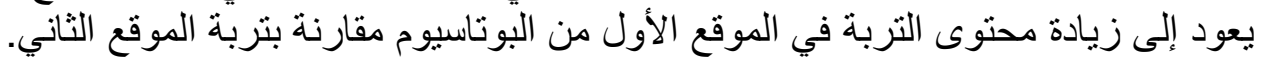

الجدول (5): نأثير التغذية الورقية بالزنك والبورون في محتوى الفوسفور ملغم.نبات-1 Table.(5):Effect of zinc and boron foliar application on phosphorous content mg.plant ${ }^{-1}$

\begin{tabular}{|c|c|c|c|c|c|}
\hline \multirow{2}{*}{$\begin{array}{c}\text { ألثير } \\
\text { اقع } \\
\text { Soil } \\
\text { effect }\end{array}$} & \multirow{2}{*}{$\begin{array}{c}\text { تأثنر الزنك } \\
\text { Zinc } \\
\text { effect }\end{array}$} & \multicolumn{3}{|c|}{$\begin{array}{c}\text { تركيز البورون (ملغم/ لتر) } \\
\text { Boron concentration (ppm) }\end{array}$} & \multirow{2}{*}{$\begin{array}{l}\text { تركيز الزنك (ملغم/ لتر) } \\
\text { Zinc conc. (ppm) }\end{array}$} \\
\hline & & 10 & 5 & 0 & \\
\hline & \multicolumn{5}{|c|}{ الموقع الاول تربة location Entisols } \\
\hline & $231.08 \mathrm{c}$ & 264.91 & 248.60 & 179.74 & 0 \\
\hline & $298.30 \mathrm{~b}$ & 380.00 & 281.78 & 233.10 & 5 \\
\hline & $347.00 \mathrm{a}$ & 472.00 & 299.33 & 269.65 & 10 \\
\hline & & $372.31 \mathrm{a}$ & $276.57 \mathrm{a}$ & $227.31 \mathrm{c}$ & Boron effect تأثير البورون \\
\hline & \multicolumn{5}{|c|}{ الموقع الثاني تربة necation Aridisols } \\
\hline & $364.47 \mathrm{c}$ & 452.04 & 349.20 & 292.14 & 0 \\
\hline & $449.96 \mathrm{~b}$ & 595.21 & 449.15 & 305.50 & 5 \\
\hline & $528.36 \mathrm{a}$ & 695.87 & 508.35 & 416.85 & 10 \\
\hline & & $569.05 \mathrm{a}$ & $435.57 \mathrm{a}$ & $338.17 \mathrm{c}$ & Boron effect تأثير البورون \\
\hline & \multicolumn{5}{|c|}{ التحليل التجميعي Accumulative analysis } \\
\hline & $297.77 \mathrm{c}$ & 358.475 & 298.9 & 235.94 & 0 \\
\hline & $374.13 \mathrm{~b}$ & 487.605 & 365.465 & 269.3 & 5 \\
\hline $\begin{array}{c}291.13 \\
b\end{array}$ & $437.68 \mathrm{a}$ & 565.935 & 403.84 & 343.25 & 10 \\
\hline $447.60 \mathrm{a}$ & & $470.68 \mathrm{a}$ & $356.07 \mathrm{~b}$ & $282.83 \mathrm{c}$ & Boron effect تأثنير البورون \\
\hline
\end{tabular}

الأحرف المتثابهة ضمن العمود أو الصف الو احد لا تختلف فيما بينها معنويا حسب اختبار دنكن وتحت بمستوى احتمال 5\%

Values with in columns or rows followed by the same letters are not significantly at $\mathrm{p}=5 \%$

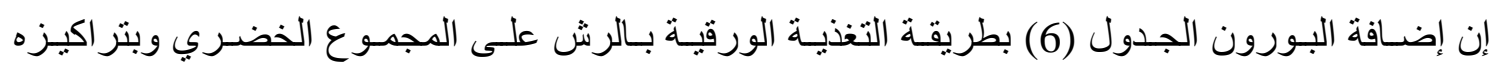

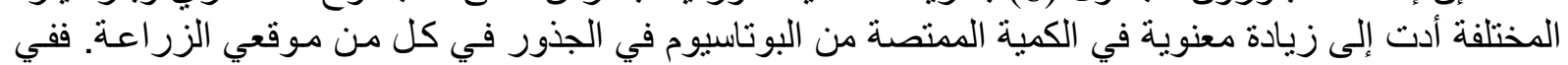

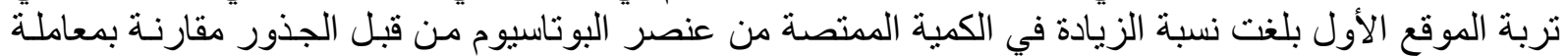

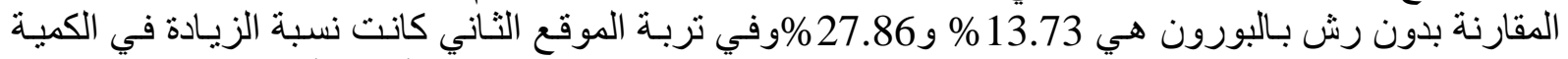

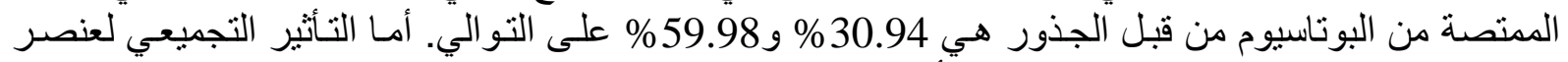

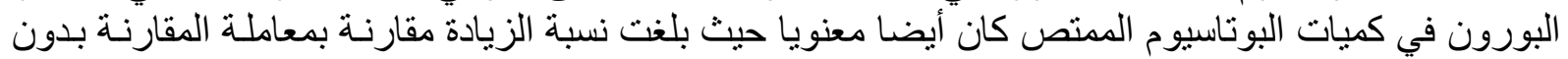

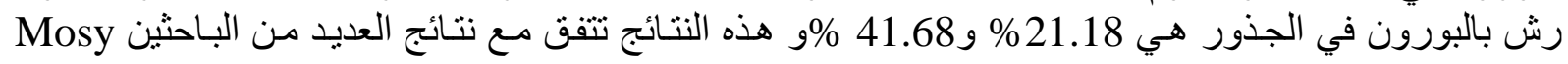


Mesopotamia J. of Agric.

Vol. (45) No. (3) 2017
ISSN: 2224 - 9796 (Online)

ISSN: 1815 - $316 \mathrm{X}$ (Print)

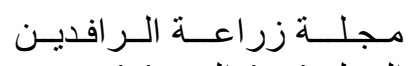

المجلد (45) العدد (3) 2017

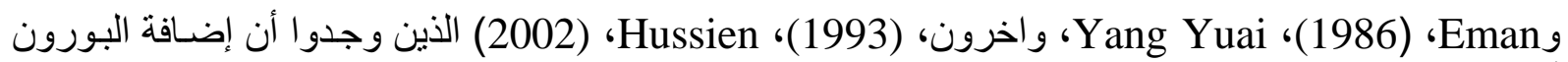
أدت إلى زيادة تر اكيز ومحتوى البوتاسيوم في الجذور فضلا عن زيادة الامتصاص الكلي.

$$
\text { الجدول (6): تأثير التغذية الورقية بالزنك و البورون في محتوى البوتاسيوم ملغم.نبات-1 }
$$

Table (6): Effect of zinc and boron foliar application on potassium content mg.plant ${ }^{-1}$.

\begin{tabular}{|c|c|c|c|c|c|}
\hline \multirow{2}{*}{$\begin{array}{c}\text { المو اقنُ } \\
\text { Soil } \\
\text { Soil } \\
\text { effect }\end{array}$} & \multirow{2}{*}{$\begin{array}{c}\text { تأثير الزنك } \\
\text { Zinc } \\
\text { effect }\end{array}$} & \multicolumn{3}{|c|}{$\begin{array}{c}\text { تركيز البورون (ملغم/ لتر) } \\
\text { Boron concentration (ppm) }\end{array}$} & \multirow{2}{*}{$\begin{array}{l}\text { تركيز الزنك (ملغم/ لتر) } \\
\text { Zinc conc. (ppm) }\end{array}$} \\
\hline & & 10 & 5 & 0 & \\
\hline & \multicolumn{5}{|c|}{ الموقع الاول تربة المبا } \\
\hline & $2080.00 \mathrm{~b}$ & 2359.2 & 2145.65 & 1740.00 & 0 \\
\hline & $2436.0 \mathrm{ab}$ & 2734.33 & 2447.64 & 2125.98 & 5 \\
\hline & $2670.80 \mathrm{a}$ & 2976.76 & 2590.00 & 2445.55 & 10 \\
\hline & & $2690.1 \mathrm{a}$ & $\begin{array}{c}2392.8 \\
\mathrm{Ab}\end{array}$ & $2103.8 \mathrm{~b}$ & Boron effect تأثير البورون \\
\hline & \multicolumn{5}{|c|}{ 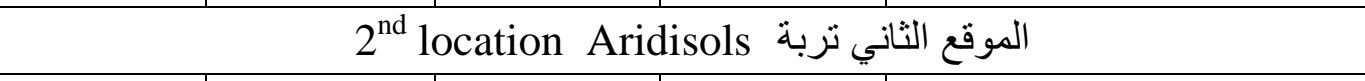 } \\
\hline & $1640.2 \mathrm{c}$ & 1976.2 & 1660.1 & 1284.33 & 0 \\
\hline & $2050.0 \mathrm{~b}$ & 2558.78 & 2167.26 & 1424.15 & 5 \\
\hline & $2520.9 \mathrm{a}$ & 3090.38 & 2414.16 & 2058.03 & 10 \\
\hline & & $2541.8 \mathrm{a}$ & $2080.5 \mathrm{~b}$ & $1588.8 \mathrm{c}$ & Boron effect تأثثر البورون \\
\hline & \multicolumn{5}{|c|}{ التحليل التجميعي Accumulative analysis } \\
\hline & $1860.10 \mathrm{c}$ & 2167.7 & 1902.875 & 1512.16 & 0 \\
\hline & $2243.0 \mathrm{~b}$ & 2646.52 & 2307.45 & 1775.06 & 5 \\
\hline $2396.6 \mathrm{a}$ & $2595.80 \mathrm{a}$ & 3033.57 & 2502.08 & 2251.79 & 10 \\
\hline $\begin{array}{c}2070.4 \\
\text { b }\end{array}$ & & $2615.90 \mathrm{a}$ & $2237.46 \mathrm{~b}$ & $1846.30 \mathrm{c}$ & Boron effect تأثير البورون \\
\hline
\end{tabular}

Values with in columns or rows followed by the same letters are not significantly at $p=5 \%$

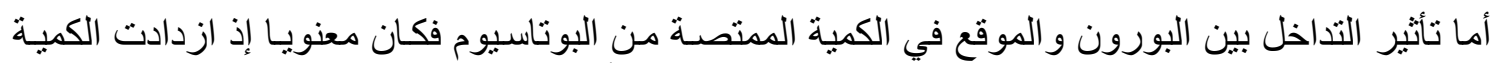

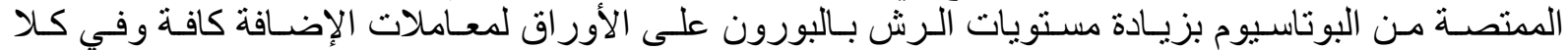

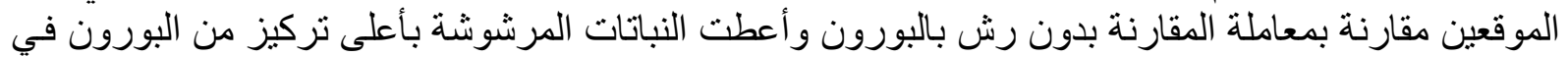

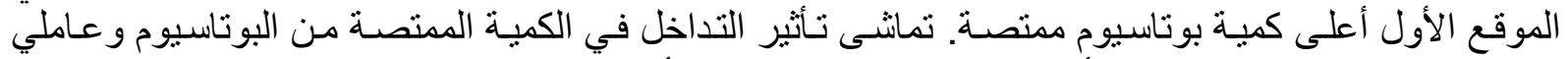

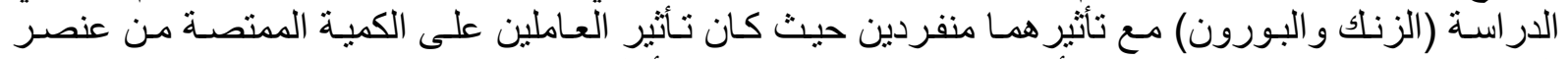

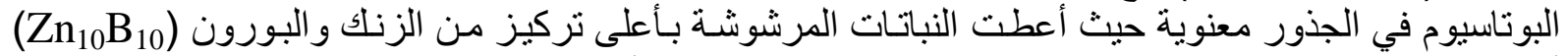

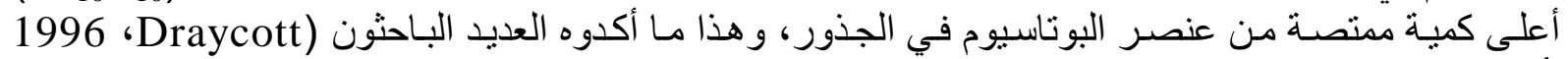

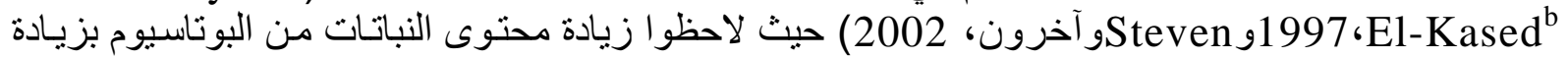

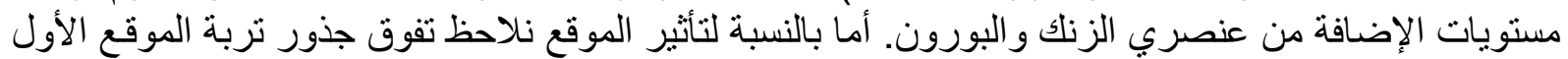

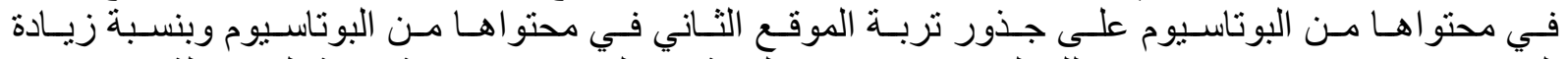

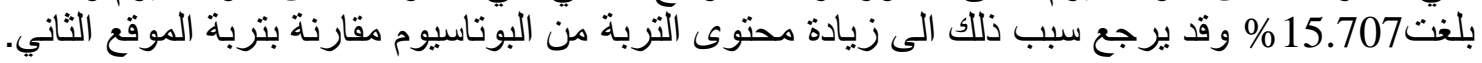




\title{
EFFECT OF ZINK AND BORON FOLIAR APPLICATION ON SOME NUTRIENTS CONTENT OF SUGER BEET PLANT Beta Vulgaris $L$.
}

\author{
Wheeda Ali Ahmed Al-Badrani \\ College of Agriculture and Forestry, Mosul University. Iraq \\ E-mail: wheeda_ali2000@yahoo.com
}

\begin{abstract}
The use of higher levels of boron and zinc fertilizer by spray to the leaves of sugar beet and their interactions caused a significant effect on yield quantity by increasing the total yield, weight per one root, and content roots of elements nitrogen, phosphorus, potassium and boron In both location study. The effect of the interaction of boron and zinc at higher concentration was more significant than each factor alone. Boron and zinc fertilizer treatment with $10 \mathrm{ppm}$ Boron and $10 \mathrm{ppm}$ Zinc gave an increase in each of the characterize at two locations. Higher response to fertilizer B and /or $\mathrm{Zn}$ application was found in the Aridsols soil of second location compared with first location Entisols, in the root yield quantity and content roots of elements (nitrogen, phosphorus, potassium and boron of sugar beet. Again the fertilizer efficiency and inter needed of the elements were higher in Aridisols soil compared with Entisols soil at all levels of added Zinc and boron fertilizers. Also the fertilizer efficiency and inter needed of the elements were higher in Aridisols soil compared with soil of Entisols at all levels of added Zinc and boron fertilizer sprayed.
\end{abstract}

Keywords: Sugar beet, Yeild, Zinc, Boron.

$$
\begin{aligned}
& \text { Received: 17/2/2013, Accepted: 24/6/2013. }
\end{aligned}
$$

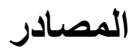

$$
\begin{aligned}
& \text { الر اشدي، صالح محمد احمد، (2001). التسميد بNP على حاملى حاصل ونوعية البنجر السكري في العراق. أطروحة }
\end{aligned}
$$

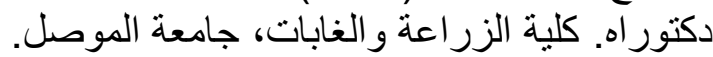

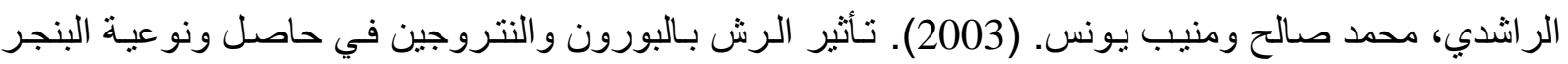

$$
\begin{aligned}
& \text { السكري. ملحق المؤتمر القطري. مجلة تكريت للعلوم الزراعية. } \\
& \text { رزق، نوكل يونس وحكمت عبد علي (1981). المحاصيل الزيتية والسكرية، وزارة التعليم العالي والبحث } \\
& \text { صالح، حمد. محمد (2004). التغذية الورقية. رئيس باحثين الثركة العامة للمحاصيل الصناعية. مجلة الزراعة } \\
& \text { العراقية. العدد الثاني. }
\end{aligned}
$$

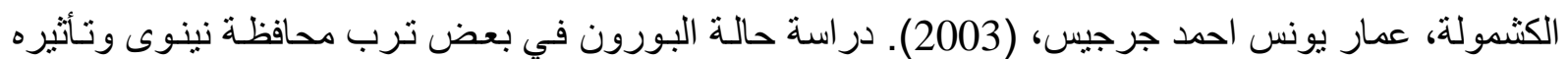

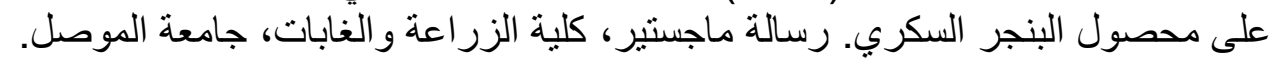

$$
\begin{aligned}
& \text { مجهول، (1986). دليل النوعية والمواصفات القياسية لفحص وتحليل السكر، معمل سكر الموصل. }
\end{aligned}
$$

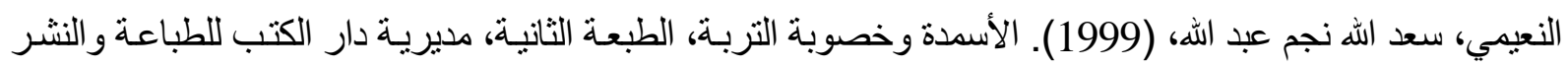

$$
\begin{aligned}
& \text { - جامعة الموصل- الطبعة الثنانية. }
\end{aligned}
$$

Anderson, S. (2005). Boron Basics. Agronomic Library. Washington Court House, OH 43160 (800) 321-1562.

Anonymous (2004) Uptake of mineral nutrients from foliar (factors related to spray solution).Journal of Fruit and Ornamental Plant Research 12: 120-126. 
Anonymous, (1995). Soil Taxonomy: Soil Conservation Service, USDA, Washington ,D.C. ,Agricultural Hand Book, No.36.

Anonymous, (2001) Statistical Analysis Systems. Statistical Analysis Institute 1nc, Cary, Ne, USA.

Bonilla, L., C. Cadahia., and O. Carpena. (1980). Effect of boron on nitrogen metabolism and sugar levels of sugar Beet. Plant and Soil, 57(10):3-9.

Cattanach, A.W., A.G. Dexter, A.G., and E.S. Opi. (1991). Sugar beets (1)Extension Sugar Beet Specialists North Dakota, Dakota State University, Fargo, No. 58105, and University (2) Department of Agronomy, College of Agricultural and Life Science Cooperative Extension July 1991.

Draycott, A. P. (1996). Fertilizing For High Yield and Quality Sugar Beet. Ball 15-IPI Basel. Switzerland..

El-Kased, F.A. (1997a). Effects of boron, zink and phosphorus on sugar beet production in calcareous soils. Annals of Agricultural Sciences, 35(4): 2631-2639.

El-Kased, F.A. (1997b). Effect of phosphorus, zink and boron on nutrient composition and requirements of sugar beet in calcareous soil. Annals of Agricultural. Sciences. 35(4): 2653-2662.

Gupta, U.C. (1993). Boron and Its Role In Crop Production. CRC Press. U.S.A..

Gupta, U.C. (1999). Method of Analysis of Soils, Plants, Waters and Fertilizers. New Delhi-110048. (India).

Havlin, J.L., Beaton, J.D., Tisdale, S.L. and W.L., Nelson. (1999) Soil Fertility and Fertilizers, An Introduction To Nutrient Management. Prentice - Hall, Inc.

HuH,S.G.Penn,C.B.Lebrilla,P.H.Brown.(1997).Isolation and characterization of soluble B-Complexes in higher plants. plants. Themechanism of ploem mobility of boron. Plant Physiol 113:649-655.

Hussein, M.A. (2002). Effect of boron on the yield, elemental, Content and quality characteristics of sugar beet grown in calcareous soil, amended with sulfur. Alex. Journal Agricutural Researches., 47(2): 201-207..

Khalil, M.S., S. N. Mostafa., and R.Z. Mostafa. (2001). 1- Department of Biochemistry Fac.of Agric minufiga univ. 2-Sugar crops Res Center Department of Biochemistry Fac. of Agric. Minufiga Univ. Giza Egypt Minufiya. Journal of Agricural Researches. 26, (3):583-594.

Krauss, A. (2001). Balanced Fertilization For Crop Yield and Quality Global and Regional Potash Consumption and Deriving K Balance In Agriculture. International Potash Institute. POB 1609, CH-4001 Basel. Switzerland.

Krauss, A. (2003). Importance Of Balanced Fertilization To Meet The Nutrient Demand Of Food Crops. IPI-NFS International workshop. International of Potash Fertilization for Sustainable Production Of Plantation and Food Crops In Sri Lanka 1-2 December 2003.

Malakouti, M.J. and Kalantari, I. (1988) Yield increase and fortification of wheat grains by composts, Fe chelated and $\mathrm{ZnSO}_{4}$ in the calcareous soils of Iran. 16th Soil Science Congress. Montpelier, France. 
Mehrotra, N.K., S.A. Khan., and S.C. Agarwala. (1989). High SAR (Sodium adsorption ratio irrigation and boron photo toxicity in sugar beet. Annal Arid Zone. 28: 69..

Morsy, M.A., and M.T. Eman. (1986). Effect of boron manganese and their combination on sugar beet under El-Mina condition. 2. Concentration and uptake of N.P.K.B. and Mn. Annal of Agricultural Sciences: 31(2): 1241-1259.

Roberts , K.R.,M.J.German., and D. D.Howard. (2000).Soil and foliar applied boron in cotton production:An Economic Analysis.The Journal of Science 4:171- 177.

Stevens, B. Killen, M. and Bjornestad, L. (2002) Use Of Micronutrient Fertilizers In Sugar Beet Production. Powell Research and Extension Center: 22-25.

Yadav, H.D., O.P. Yadav, O.P. Dhankar., and M.C. Oswal. (1989). Effect of chloride salinity and boron on monition growth and mineral composition of chickpea (Cicer arietmum. L.). Annals Arid Zone, 28:63.

Yang Yuai, Xue Jianming, Ye Zhengiang., and Ke Wang. (1993). Responses of rap genotypes to boron application. Plant and Soil, 155/156: 321-324. 
Mesopotamia J. of Agric.

Vol. (45) No. (3) 2017
ISSN: 2224 - 9796 (Online)

ISSN: 1815 - 316 X (Print)

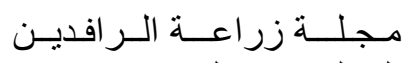

المجلد (45) العدد (3) 2017 